\title{
Spatial and temporal dust source variability in northern China identified using advanced remote sensing analysis
}

\author{
A. Taramelli, ${ }^{1 *}$ M. Pasqui, ${ }^{2}$ J. Barbour, ${ }^{3}$ D. Kirschbaum, ${ }^{3}$ L. Bottai, ${ }^{2,4}$ C. Busillo, ${ }^{2,4} \mathrm{~F}$ Calastrini, ${ }^{2,4} \mathrm{~F}$ Guarnieri ${ }^{2,4}$ and C. Small ${ }^{3}$ \\ 1 ISPRA - Institute for Environmental Research, Rome, Italy \\ 2 Institute of Biometeorology and National Research Council/IBIMET-CNR, Florence, Italy \\ 3 Lamont Doherty Earth Observatory of Columbia University, New York, USA \\ ${ }^{4}$ Consortium LaMMa - Laboratory for Meteorology and Environmental Modelling, Sesto Fiorentino, Italy
}

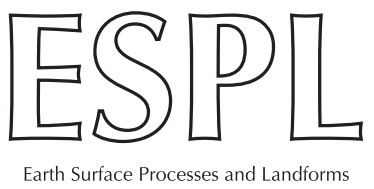

ABSTRACT: The aim of this research is to provide a detailed characterization of spatial patterns and temporal trends in the regional and local dust source areas within the desert of the Alashan Prefecture (Inner Mongolia, China). This problem was approached through multi-scale remote sensing analysis of vegetation changes. The primary requirements for this regional analysis are high spatial and spectral resolution data, accurate spectral calibration and good temporal resolution with a suitable temporal baseline. Landsat analysis and field validation along with the low spatial resolution classifications from MODIS and AVHRR are combined to provide a reliable characterization of the different potential dust-producing sources. The representation of intra-annual and inter-annual Normalized Difference Vegetation Index (NDVI) trend to assess land cover discrimination for mapping potential dust source using MODIS and AVHRR at larger scale is enhanced by Landsat Spectral Mixing Analysis (SMA). The combined methodology is to determine the extent to which Landsat can distinguish important soils types in order to better understand how soil reflectance behaves at seasonal and inter-annual timescales. As a final result mapping soil surface properties using SMA is representative of responses of different land and soil cover previously identified by NDVI trend. The results could be used in dust emission models even if they are not reflecting aggregate formation, soil stability or particle coatings showing to be critical for accurately represent dust source over different regional and local emitting areas. Copyright (C) 2012 John Wiley \& Sons, Ltd.

KEYWORDS: dust source; spectral mixing analysis; NDVI time series; China

\section{Introduction}

A key area of interest concerning dust storms is the characterization of interactions between the land surface and the atmosphere in dust source areas, in other words, detecting the 'hotspots' (Qian et al., 2002; Washington et al., 2006; Fratini et al., 2009; Lee et al., 2009). Mapping land surface properties provides input for physical process models, while monitoring changes in land cover facilitates identification of progressive trends on seasonal and inter-annual timescales (Wells et al., 2007). Both are necessary to identify potential dust sources and monitor their changes through time (Gillette, 1999; Schepanski et al., 2007; Katra and Lancaster, 2008). In recent years, the increasing interest in dust activity evaluations and efforts to retrieve information about dust from remotely sensed data have improved the understanding of the global distribution of source regions for soil-derived dust (Goudie and Middleton, 2001; Miller et al., 2006). These datasets and associated products used include multispectral imagery from the Multi-angle Imaging Spectroradiometer (MISR) (Meloni et al., 2004), the Moderate-Resolution Imaging Spectroradiometer (MODIS) (Bullard et al., 2008; Baddock et al., 2009) or indices such as the Total Ozone Mapping Spectrometer Aerosol Index
(TOMS Al) and the Infrared Difference Dust Index (IDDI) (Legrand et al., 2001; Prospero et al., 2002; Kaufman et al., 2005). In particular, recent applications of TOMS Al combined with information on land use and land cover (Israelevich et al., 2002; Todd et al., 2007) present a global remotely sensed picture of dust distribution (calculated on recirculated dust for several days). Most are concentrated in modern or ancient sediment-depositional environments, and are located mainly in arid regions characterized by topographic depression surfaces and where there is sparse or no vegetation cover (e.g. Gillette, 1999; Prospero et al., 2002; Washington et al., 2006). However, uncertainties remain in the understanding of the spatial distribution of dust sources within the source regions and about their surface attributes, in particular the surface-sediment-vegetation interactions which can determine the emission potential (Wang et al., 2007; Bullard et al., 2008; Okin et al., 2011). These gaps in understanding the geomorphological context of sources areas are, in turn, a source of uncertainty in global climate change modelling. Although simulation of atmospheric dust loading has improved (Ginoux et al., 2001; Tegen et al., 2002; Zender et al., 2003; Rivera Rivera et al., 2009) and dust source variability in space and time has been recognized (Mahowald et al., 2003; 
Bryant et al., 2007; Reynolds et al., 2007), comparatively little is known about dust source area characteristics (Okin et al., 2011). Major issues include identification of the most productive areas within an observed dust source area; controlling factors on dust emissions in space and time; mass, size and soil composition of emitted dust; and sensitivity of dust sources to environmental (climate and land cover/use) changes (Reheis and Kihl, 1995; Okin et al., 2006). In this context a number of studies have shown that there is a strong link between the seasonal variability of vegetation and the occurrence of dust storms using the Normalized Difference Vegetation Index (NDVI) (Malo and Nicholson, 1990; Nicholson and Farrar, 1994; Schmidt and Karnieli, 2000; Kawabata et al., 2001). Vegetation cover protects the underlying soil and is capable of intercepting dust and precipitation (Engelstaedter et al., 2003; Xu et al., 2003, 2006). The density of the vegetation protects the surface from deflation, while the presence of structured vegetation results in a high surface roughness that reduces surface wind energy and therefore also dust emissions (Engelstaedter, 2003). In contrast, shrublands tend to have less dense vegetation and more bare soil (Okin et al., 2011), relating the emission and transport of dust to the wind strength (Figure 4 in Pasqui et al., 2012). Reduction in perennial vegetation cover has been used to predict the onset of desertification (Xu et al., 2006; Urban et al., 2009) and to map land surface moisture in varying terrains (Valor and Caselles, 1996; Peters et al., 1997). Decrease in value of the NDVI could therefore highlight areas where different pressures have had a significant impact on the land cover or where large-scale hydrological and atmospheric changes are occurring (e.g. decrease in snowfall). The identification of areas where NDVI values are increasing or decreasing through time could provide evidence of where dust storms may originate in the future (Townshend and Justice, 1986; Schmidt and Karnieli, 2000; Xu et al., 2006; Urban et al., 2009; Okin et al., 2011). Mapping and tracking changes in waning-signal vegetated areas could lead to future dust sources area identification (Nicholson et al., 1990; Tucker et al., 1991; Maselli et al., 1993; Chladil and Nunez, 1995; William and Thomas, 1996; Weiss et al., 2001) and represent the land cover evolution during seasonal, annual and decadal changes over wide regions (Bach et al., 2007).

Reduction in vegetation cover is not the only control on dust emissions; consequently, once vulnerable areas have been identified on the basis of vegetation loss, it is then critical to assess the geomorphology, land use and soil characteristics of the area (Okin et al., 2006; Reynolds et al., 2007; Scheidt et al., 2007; Schepanski et al., 2007; Katra and Lancaster, 2008; Bullard et al., 2011). Of the available remote data sources, Landsat imagery is best suited to this task because it provides a calibrated 30 -year baseline and both the spatial and temporal resolution necessary to distinguish among important land cover and soils types and to characterize their temporal variability on seasonal to inter-annual scales (Small and Lu, 2006; Small et al., 2009; Taramelli, 2011). While high spatial resolution (1-10 m) imagery like Ikonos and Quickbird are able to distinguish individual land cover elements (e.g. buildings, roads), the narrow swath width $(10-40 \mathrm{~km})$ precludes synoptic regional analysis and the limited spectral resolution (four broad bands in the very near infrared, VNIR) does not provide the short-wave infrared (SWIR) reflectance necessary to discriminate many rock/soil substrates. In principle, other moderate-resolution sensors, like SPOT and Aster, could provide many of the same benefits as Landsat but the cost, non-uniform acquisition and lack of calibration often preclude their use.

As part of a joint Chinese-Italian project (WINDUST; Fratini et al., 2005, 2009; Bach et al., 2007) aimed at estimating the dust emission potential of arid and semiarid areas of northern Asia, the remote sensed imagery from several instruments and missions
(MODIS, LANDSAT, AVHRR), in combination with ground data, were integrated to develop an innovative and quantitative method to understand the geomorphological context of dust source areas located in northwest China (Alashan Prefecture, Inner Mongolia; Figure 1). The aim of this paper is to show the remote sensing analysis results to characterize the source areas' surface properties, and to highlight the potential for emission area detection at the local (hotspot) and regional (source area) scale. Here the effort was a two-step approach:

(a) studying seasonal and inter-annual dynamics at a regional scale using low-resolution remotely sensed data to highlight the response of different plant functional types that is critical to simulate dust emission over vegetated areas;

(b) studying morphological properties within the soil-vegetation change areas using the medium-resolution remotely sensed data in combination with innovative assimilation of data from ground observations to develop a quantitative method to define local hotspots and characterize their surfaces. We addressed the last issue by using (1) spectral mixture analysis to represent land surface reflectance as continuous fields of biophysical land surface properties based on the selection of the most suitable end members (spectral signature for a pure surface cover), (2) field spectroscopy validation to verify the accuracy of the mixture model and (3) decision tree classification to divide the spectral mixing space into discrete dust particle physical properties, (also considering Fratini et al., 2009), in order to develop methods for automated monitoring of dust sources with orbital data.

The overall and final objective of this part of the WINDUST project was to map the spatial extents of spectrally distinct rock and soil substrates that may represent dust sources for use in a model (RAMS - regional Atmospheric Modeling System) with a continuous land cover grid at $30 \mathrm{~m}$ resolutions in order to assess and quantify the impact of environmental changes over China (Pasqui et al., 2012).

\section{Methods and Results}

\section{Trend analysis from NDVI}

In order to characterize the temporal trends in vegetation losses and potential response of different plant functional types to intra-annual and inter-annual climate variations, a time series of NDVI was analyzed as a measure of the vegetation abundance and to discriminate spatiotemporal changes in vegetation cover that could simulate dust emission (Bullard et al., 2008; Rivera Rivera et al., 2009; Okin et al., 2011). The NDVI product was derived from AVHRR images and processed at the University of Maryland in the Global Inventory Modeling and Mapping Studies (GIMMS). At the time of analysis, the GIMMS NDVI archive provided bimonthly composite images, corrected for several errors, from 1 August 1981 to 31 December 2003 at $8 \mathrm{~km}$ spatial resolution (Tucker et al., 2004).

To develop a regional baseline for vegetation trends, we evaluated spatial and temporal patterns in GIMMS $8 \mathrm{~km}$ resolution NDVI from the western Alashan Desert to the coast east of Beijing, an area between $37-43^{\circ} \mathrm{N}$ and $96-117^{\circ} 30^{\prime} \mathrm{E}$. To prepare the data for analysis, each global bimonthly GIMMS image was clipped to the study region and joined to create a stack of 540 time-slice images. The dataset was evaluated on a pixel-by-pixel basis (Bach et al., 2007). To obtain a qualitative understanding of how NDVI has changed over the past two decades, we computed April averages for three years at the beginning (1982-1984), middle (1992-1994) and end 


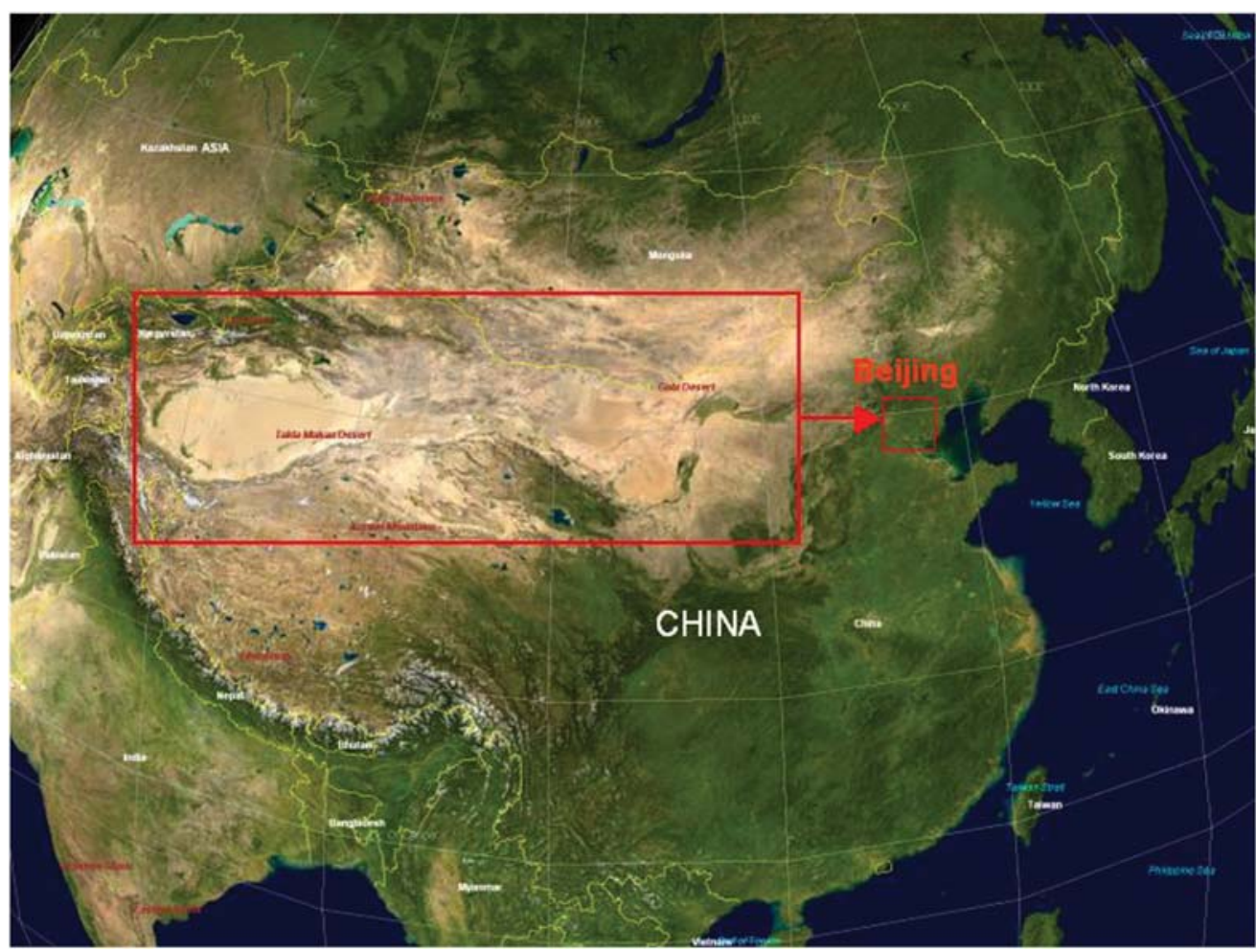

Figure 1. Location of the study area. The Alashan Desert is acknowledged as a major source of dust-sand storms that affect Beijing. The large box around the Alashan shows the dust-sand source study region and the small box around Beijing shows the dust-sand target region of interest.

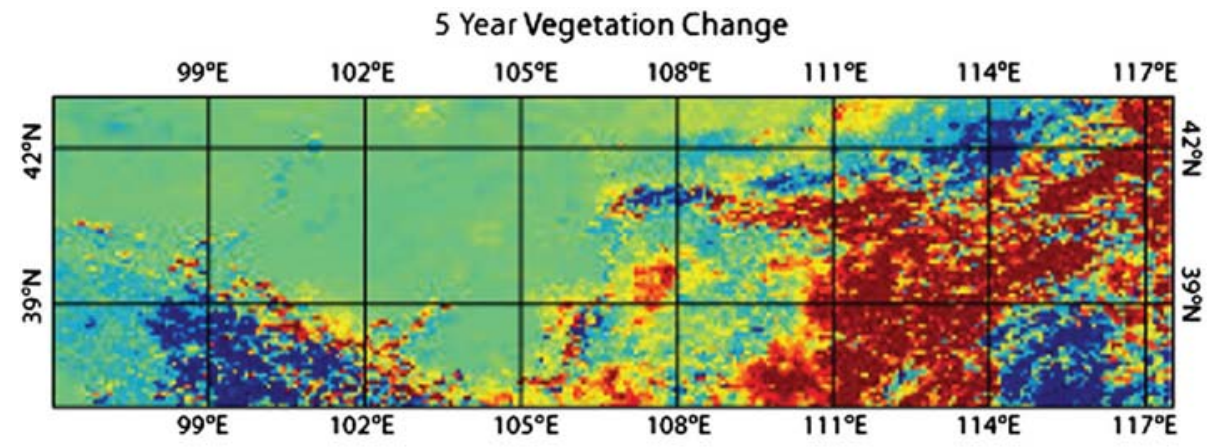

8 Year Vegetation Change

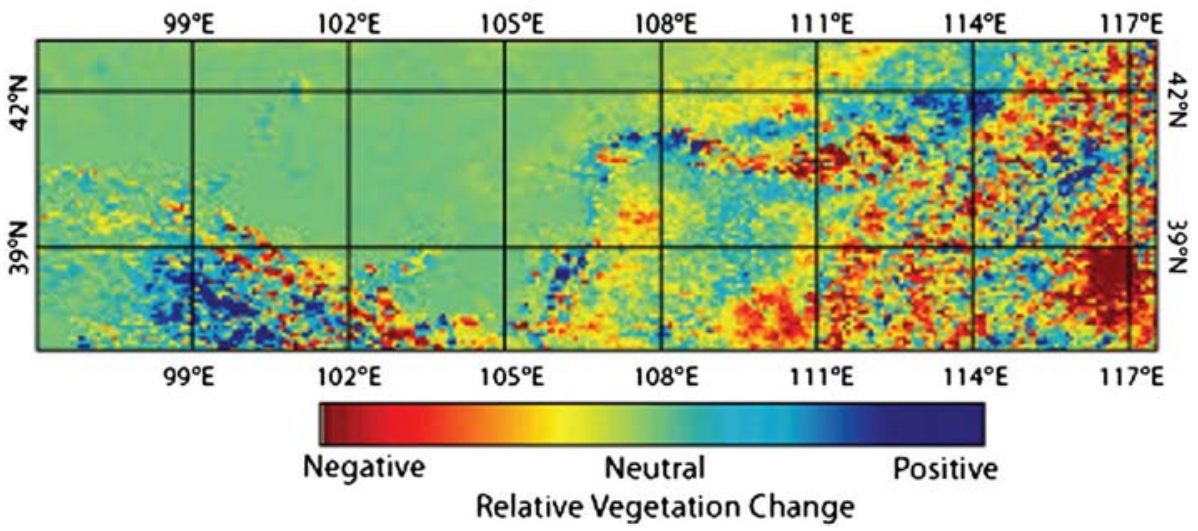

Figure 2. The figures depict relative vegetation change based on the least-squares linear regression fit to the running variance (colour scale equates to the slope of the regression line) calculated from the 5 -year running variance where 0.2 is the threshold between negative and neutral, 0.4 is the neutral value and the 0.6 is the threshold between neutral and positive. The top figure used a baseline of 5 years to calculate the regression, while the bottom figure used 8 years of data. These figures provide differing depictions of potential vegetation changes in the southeast portion of the region of interest. 
(2001-2003) of the time series based on the most representative dry seasons that were coincident with April in the literature (Tucker et al., 1994; Lee et al., 2002; Xu et al., 2006). We then converted these April averages to an RGB composite image based on the seasonal variation in the occurrence of dust storm events in China (Qian et al., 2002; Xu et al., 2006; Fratini et al., 2007). By displaying the 1982-1984 image in red, the 1992-94 image in green and the 2001-2003 images in blue, we gain a qualitative understanding of the NDVI trends within dry years. This is a method pioneered by Elvidge et al. (1997a, 1997b) at NOAA's National Geophysical Data Center, who have used time-slice RGB composites to visualize temporal changes in night-time light emissions across the globe (www.ngdc.noaa. gov/dmsp/publications.html). Figure 2 depicts these changes in NDVI over 5- and 8-year time series. The images (Tucker et al., 2005) highlight significant increases in NDVI in the southeastern portion of the image south of Beijing, along the northern portion of the Qulian Shan mountainous region in the southeastern corner of the image, and along the southern margin of the Yellow River between approximately $107-108^{\circ} \mathrm{E}$ and $40^{\circ}$ $30^{\prime} \mathrm{N}$. The images also identify decreases in NDVI from the earlier to later period of this analysis in the Beijing region and generally to the north into southern Mongolia.

We then used the NDVI dataset to identify the spatial distribution and temporal patterns of vegetation using empirical orthogonal function (EOF) analysis. Any multidimensional database can be expressed as a linear sum of elementary basis functions referred to as EOFs. These functions are orthogonal to one another, meaning that when multiplied together their product is equal to zero. The functions are also similar to a Fourier analysis, except that in Fourier analysis the basis functions are sines and cosines of different frequencies and phases. The results of the orthogonal decomposition of the dataset can be used to identify independent spatial and temporal patterns. The first EOF represents the dominant spatial pattern in the data, which contains the largest portion of the dataset variance. Correspondingly, the first principal component (PC) or dominant loading pattern describes the leading pattern in the time series. EOF analyses are computationally intensive and the full-resolution NDVI dataset could not be handled by the available software. To perform the analysis, we resample each time-slice image to 7 arcmin (approximately $10 \mathrm{~km}$ ) spatial resolution using a nearest-neighbour assignment. The results of the EOF analysis indicate that $64 \%$ of the variance in the dataset is described by the first EOF. This image has a strongly seasonal signal that is evident in time series on the top graph of Figure 3. The bottom image in Figure 3 represents the spatial distribution of this dominant sinusoidal trend and explains the seasonality and distribution of vegetation within the test region. Thus the value of the first EOF reflects the relative abundance of vegetation at each pixel.

In order to quantify and compare the strength of the seasonal NDVI signal at each pixel through time and compare them to the multi-year mean NDVI between 1982 and 2000 that were correlated to the frequently storms event according to $\mathrm{Xu}$ et al., 2006, we used statistical methodology to determine the difference between low NDVI values between autumn and winter, and high values between spring and summer. The seasonal signal is stronger where vegetation is more dense and weaker where it is less abundant. Thus the strength of the seasonal signal can be represented by the variance of a subset of the data through time. Variance is described as the square of the standard deviation of NDVI over a specified window of data. Variance values can range from 0.03 to 0.08 in highly vegetated areas and are 0.0005 or lower in more arid regions. For this analysis we used variance rather than mean to identify longer temporal trends in NDVI because variance is a better indicator of how vegetation

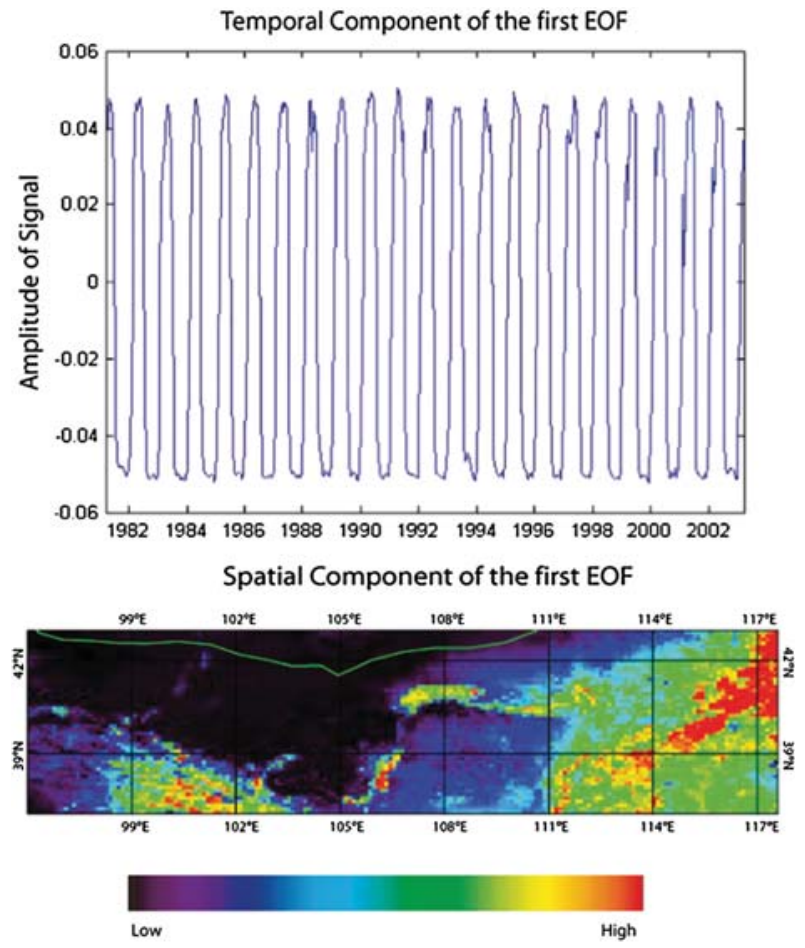

Figure 3. Top figure shows the temporal component of the first EOF, which represents $64 \%$ of the dataset variance. The strong cyclical trend of the data suggests that seasonal signal is the dominant signal of the data. The bottom figure represents the spatial component of the first EOF, showing high NDVI values in the eastern region of the sample are, along the Yellow River between $105^{\circ}$ and $109^{\circ} \mathrm{E}$ and in the southwestern margin of the image where the Tibetan plateau begins. This figure is available in colour online at wileyonlinelibrary.com/journal/espl

abundance changes seasonally. Thus, if a region that initially has sparse vegetation becomes cultivated due to agricultural expansion, the amplitude of the seasonal NDVI signal would get larger and correspondingly the variance would increase. The same trend can be documented for regions where urbanization causes vegetation to diminish and thus the NDVI variance decreases.

To quantitatively assess changes in vegetation cover through time we computed the variance of the time series at each pixel using a 5-year Hamming weighting function, which is a raised-cosine low-pass filter (Bach et al., 2007). A weighted filter was used in this situation to prevent errors, such as spectral leakage or ringing that results from using a simple boxcar filter, and which essentially decrease the signal variance and introduce more noise into the results. We tested several filter sizes on the data and concluded that a 5 -year running variance filter most effectively suppressed seasonality. The filter was able to suppress seasonality or inter-annual signals in the data without masking decadal signals such as El Niño, which generally occur on 7-year cycles. Given the 5-year window used, the resulting variance time series is curtailed at both ends and the total number of bands in the dataset decreases to 421 or 17 years. Although the shape of the Hamming window may introduce some error to the time series, it is clear that there are trends in NDVI variance in several parts of the study area. Figure 4 illustrates examples of changing smoothed variance over time in three separate pixels with very different variance values. Variance values are larger for highly vegetated regions like the Yellow River, moderate for somewhat vegetated regions such as Beijing, and almost zero for desert regions in the Alashan. When the Yellow River and Beijing example pixels are fitted to more appropriate scales, strong increasing and decreasing trends respectively are apparent. 


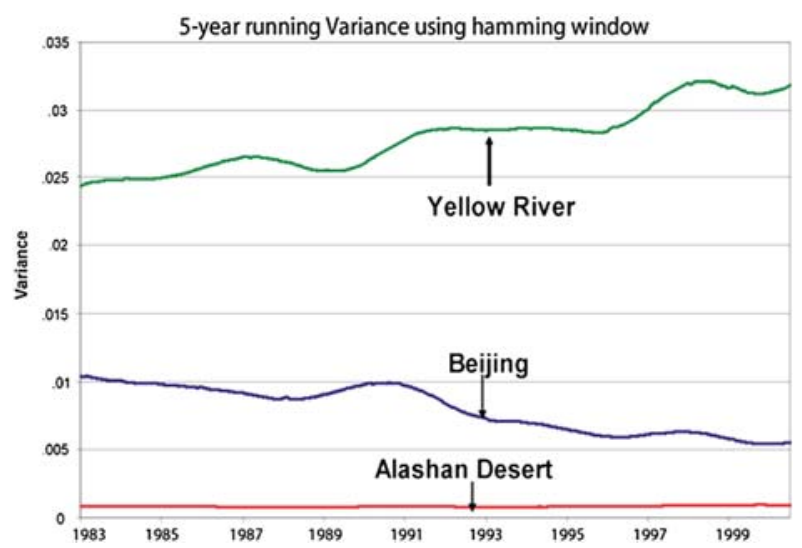

Figure 4. The 5-year running variance from the three test pixels with different values of NDVI.

Using the same variance time series and techniques, we then produced time series for regions that appear to have experienced significant change in NDVI over the whole 22-year time span based on the RGB colour composite (Figure 5). Figure 6 shows plots of individual pixels within six different regions of Figure 5 that appear to have increasing or decreasing variance trends. For regions (d)-(f) we averaged nine pixels together to reduce signal noise. To more closely identify variance trends, regression lines were fitted to the averages in Figure 6(a) and (b). It is important to note that while the average values and linear regressions for change plots illustrate a general trend in variance values, they do not capture the actual scale of temporal variance estimates and there remains a large variability amongst the test pixels (Bach et al., 2007). Results (Figures 5 and 6) suggest that the Beijing area (a) has experienced a consistent decrease in NDVI variance from the early 1980 s to 2000 s corresponding to a reduction in seasonality. The region south of Beijing in the Hebei Province, region (d), appears to have experienced an increase in variance until the early to mid 1990s, whereupon the variance values dropped and then regained a positive trend. This could either be due to a multi-year climatological influence such as El Niño, or snowmelt reduction. The Yellow River also exhibits some interesting NDVI variance trends. The portion of the Yellow River which follows an arc at roughly $40^{\circ} 30^{\prime} \mathrm{N}$ is characterized by increasing variance along the Yellow River (b) and a decreasing variance to the north (c). Another area characterized by NDVI variation is located in the southern part of Alashan Prefecture, between $103^{\circ}$ and $106^{\circ} \mathrm{E}$ longitude. As more soil is covered by vegetation, dust storms become less likely because higher wind thresholds are required to carry sand and dust particles.
At this stage the smoothed NDVI variance time series appears to give a relatively useful indication of significant temporal changes in degree of seasonality within a region; thus we used the 5-year running variance to estimate possible vegetation changes in the future. We fit each pixel in the study area with a least-squares linear regression line and extrapolated the slope of the trend line to make general estimations of how NDVI variance may change (Figure 7). We used the last 5 and 8 years of the dataset for this regression in order to present two different scenarios to depict whether the variance was positively, negatively or not changing in the future. It appears that the majority of change is occurring in the eastern portion of the image where both vegetation and population are the greatest. In the 2-year data plot there are positive slope values in the southeastern portion of the image and negative slopes to the west between $111^{\circ} \mathrm{E}$ and $115^{\circ}$ E. Contrastingly, the slopes of the 5-year and 10-year data analysis suggest that there is a strong negative trend south of $39^{\circ} \mathrm{N}$ and $117^{\circ} \mathrm{E}$, while the region to the west of this area has a relatively ambiguous pattern. In general, the slopes of the 2-year data figure show more dramatic changes in slopes which most likely correspond to the shorter length of the data used for the analysis, while the slope of the 8-year data shows less dramatic changes, confirmed by the linear model and vegetation development stage (VDS) using the GIMMS NDVI anomalies (de Jong et al., 2011). Both projected NDVI maps for the highlighted six regions in Figure 5 were compared, using a $500 \mathrm{~m} \times 500 \mathrm{~m}$ and a $0.005^{\circ} \times 0.005^{\circ}$ resolution for the former and the latter, respectively. For the projected grids the total NDVI surfaces were computed considering a cell area equal to $250000 \mathrm{~m}^{2}$, and to the six latitude/longitude grids the ASPHAA algorithm was applied (Santini et al., 2010). When considering the GIMMS NDVI anomalies, the difference in percent seems to increase with the increase of the NDVI index itself $(b, f$ and $d$ regions in Figures 5 and 8) for frequency, following an exponential law and having correlation coefficients equal to 0.85. Given these results it is clear that the length of data used in the linear regression has a considerable impact on the resulting slopes and therefore estimations of future trends in seasonality.

\section{Spectral mixture analysis, classification and field} validation of Landsat ETM + for the Alashan Desert

Data

The analyses are based on Landsat ETM + imagery. Baseline imagery, ca. 2000, was acquired from the Global Land Cover Facility (GLCF) at the University of Maryland. These data were supplemented by individual scenes acquired in the spring of 2004. The imagery acquired from GLCF was originally processed by the EarthSat Corporation as inputs to the Geocover global Landsat mosaic. Technical details of the imagery are available at:

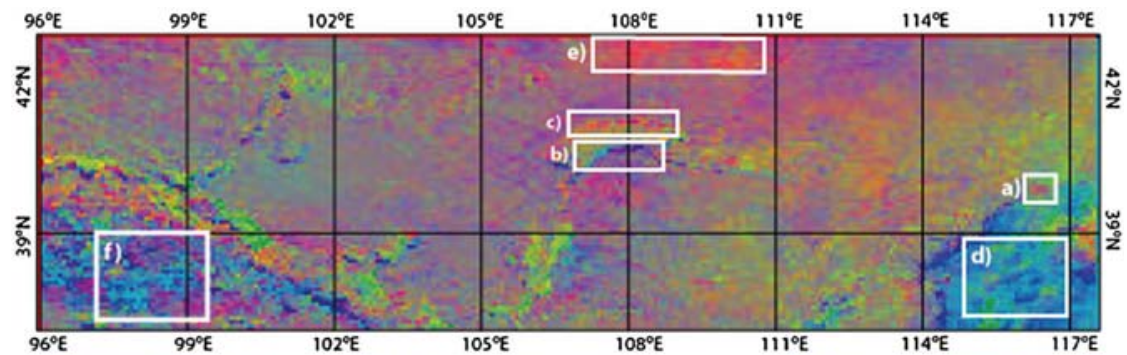

Figure 5. RGB composite within the six regions where there appears to be noticeable changes from the beginning to the end of the period. These regions are evaluated on a pixel-by-pixel basis in Figure 6 (Bach et al., 2007). 

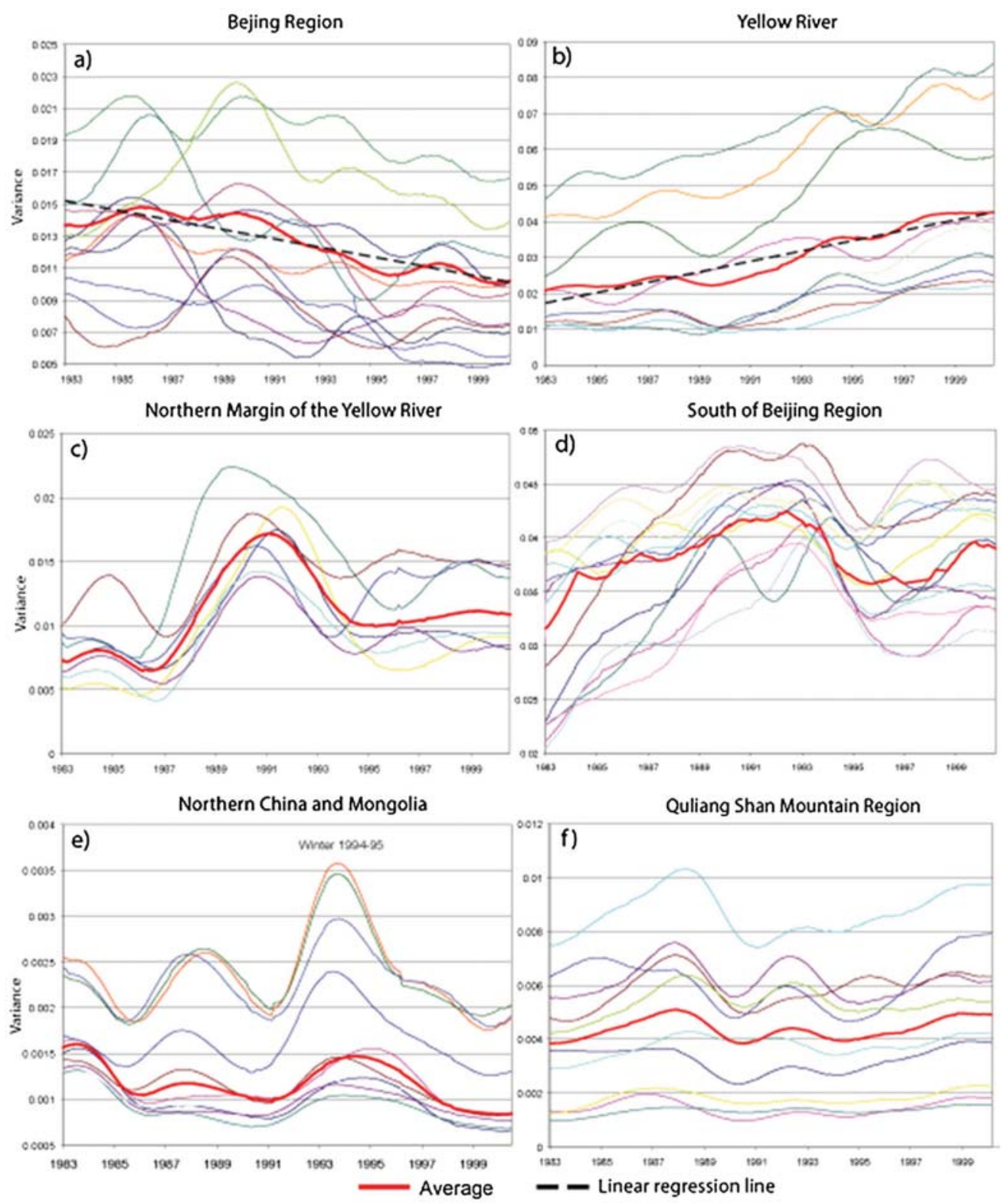

Figure 6. Time series of 5-year running variance in six different locations identified in Figure 5. Each of the coloured lines is a different pixel within the region and the solid line in each graph represents the average for the pixels in each plot. The left column shows regions where variance appears to be decreasing and the right column indicates areas where variance may be increasing. Best-fit linear regressions were fit to the average in plots (a) and (b) to highlight possible 20-year trend within the data (Bach et al., 2007). This figure is available in colour online at wileyonlinelibrary.com/journal/espl

http://glcf.umiacs.umd.edu/data/guide/technical/landsat.shtml. Details of the orthorectification and at-sensor radiance calculated by restoring linear gains and biases to image Digital Numbers are based on Chander et al., 2009.

Exo-atmospheric reflectance is derived from at-sensor radiance by compensating for seasonal variations in Earth-Sun distance and normalizing for solar irradiance as described above.

An unexpected problem arose in the calibration sequence when it was discovered that Geocover scenes acquired prior to $7 / 1 / 2000$ are not consistent with those acquired after this date. New calibration constants were released for the ETM + scenes acquired since $7 / 1 / 2000$ and these constants were used in our calibration. However, we found a serious problem with the scenes acquired before this date. Post-2000 scenes provide generally consistent exo-atmospheric reflectance values when compared to overlapping scenes but pre-2000 scenes produce consistently higher reflectance values than post-2000 scenes.
Two Geocover scenes from the Alashan region were acquired pre-2000. Comparison of sidelap in the pre- and post-2000 Alashan scenes revealed a quasi-linear band-to-band disagreement in the pre-2000 scenes. As a result, it was possible to partially correct the two pre-2000 Alashan scenes. The partial correction was accomplished by fitting a linear trend to the distribution of pre- and post-2000 pixels within the overlap regions in each band and applying a linear correction to offset the estimated trend. This improved the agreement between the pre- and post-2000 scenes but did not completely solve the problem. The magnitude of this effect is apparent in Figure 9. Fortunately, both affected Alashan scenes were on the southern periphery of the study area and not near the main regions of interest. When notified of the problem with the pre-2000 scenes, a representative at the GLCF suggested that the problem with the pre-2000 scenes may be a result of Level 1 Product Generation Systems (LPGS) versus National Landsat Archive Processing 


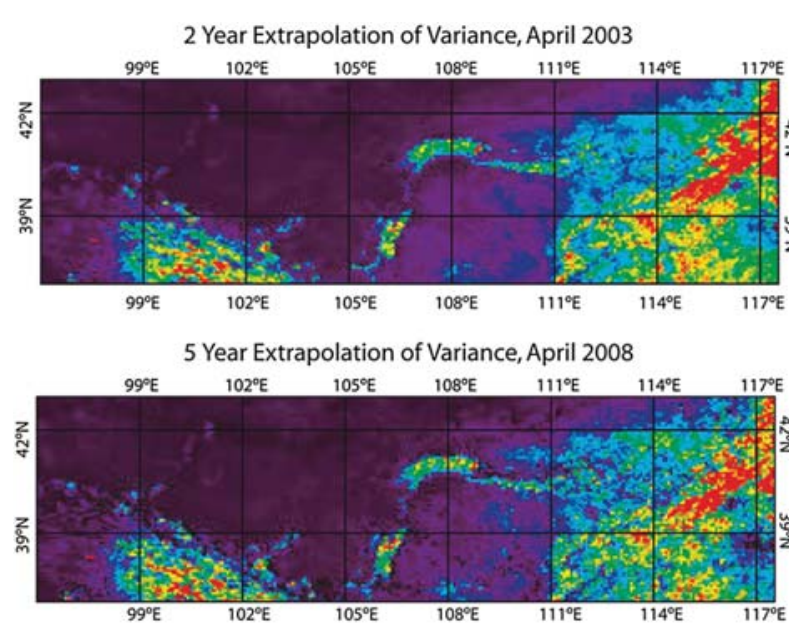

10 Year Extrapolation of Variance, April 2013

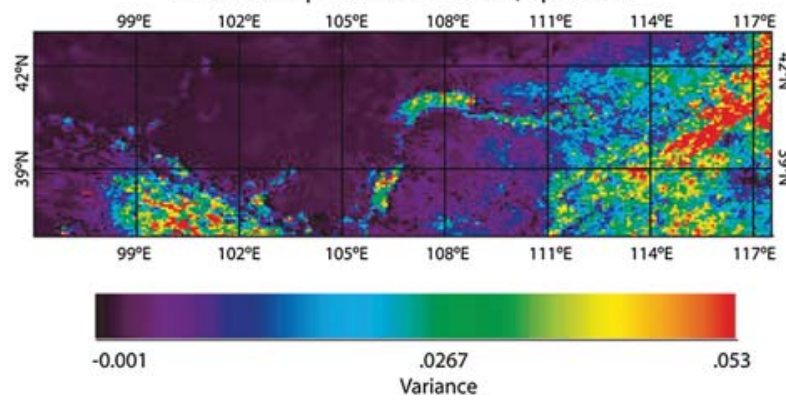

Figure 7. Changes in variance extrapolated 5 and 10 years into the future. The values were calculated by fitting a linear trend through the last 5 years of the data and extending the best-fit line into the future.

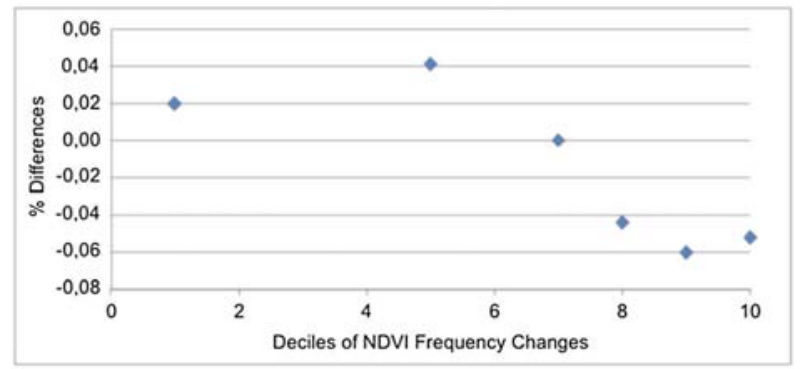

Figure 8. Percentage differences between areas computed using calculated NDVI and GIMMS NDVI for the different deciles.

System (NLAPS) processing in the original scenes acquired and processed by EarthSat. The final Alashan study area required a mosaic of 16 ETM + scenes (Figure 9 and Table I).

Another problem arose with the mosaicing of the Alashan scenes. The geographically referenced mosaicing algorithm in ENVI produced numerous projection-related errors when all 16 scenes were mosaiced simultaneously. We believe this is a result of the mosaic spanning more than one UTM zone. The problem was resolved by sequentially mosaicing scenes within individual paths (130-134) and then sequentially mosaicing the paths from west - building up the mosaic one path at a time. It was necessary to resample the Landsat scenes to $191 \mathrm{~m}$ resolution prior to mosaicing. Full-resolution data were used for analysis of individual scenes in 'hotspot' regions but reduced-resolution imagery was used for the regional mosaic. Calibration and mosaicing of the 16 ETM+scenes was by far the most

time-consuming phase of the analysis. However, the result produced outstanding sidelap and endlap agreement among adjacent scenes in the Alashan mosaic. While some scene transitions are visible in the mosaic (Figure 9), it is remarkable that the band-to-band brightnesses agree so closely. As a result, no histogram matching was necessary. Aside from the two pre-2000 scenes, only one scene (p131r33) contrasts strongly with adjacent scenes. This appears to be a result of a large increase in soil moisture in this scene, as indicated by its lower albedo and the presence of large bodies of standing water within the dune field that dominates the scene.

Spectral mixture analysis (SMA)

SMA is a methodology whereby an observed radiance is modelled as a linear mixture of spectrally pure endmember radiances. Linear mixture models are based on the observation that, in many situations, radiances reflected from surfaces with different 'endmember' reflectances mix linearly in proportion to the area of each endmember within the instantaneous field of view (IFOV) (Singer and McCord, 1979; Singer, 1981; Johnson et al., 1983). This observation has made possible the development of a systematic methodology for spectral mixture analysis (Adams et al., 1986, 1993; Gillespie et al., 1990; Smith et al., 1990; Sabol et al., 1992) in which land surface reflectance variations are described by a set of endmember fraction images representing spatial variations in the areal abundance of each endmember. Although the physical process represented by the mixture model corresponds to the measurement of a mixed radiance within the sensor IFOV, the model can also be applied to exo-atmospheric reflectances because the conversion equations are linear. If a limited number of spectrally distinct endmembers can be found it is possible to define a mixing space within which mixed pixel spectra can be described as linear mixtures of the endmember spectra. A mixing space is analogous to a spectral feature space but is generally represented with low-dimensional projections of the principal components (PCs) of the image rather than the observed radiance bands. Representing a multispectral feature space with low-order PCs allows the topology of the space to be rendered as a $3 \mathrm{D}$ construct. With Landsat imagery, the three primary PCs generally contain more than $95 \%$ of the variance in the image (Small, 2004; Taramelli and Melelli, 2009).

Given sufficient spectral resolution, a system of linear mixing equations and endmembers can be defined and the best-fitting combination of endmember fractions can be estimated for each of the observed reflectance spectra. The solution to the linear mixing problem can be cast as a linear inverse problem in which the system of mixing equations is inverted to yield estimates of the endmember fractions that best fit the observed mixed reflectances (Boardman, 1993; Settle and Drake, 1993; Boardman and Kruse, 1994). It is important to note that even when the surface within the ground instantaneous field of view (GIFOV) is not a mixture of the unique, spectrally pure endmember materials, it can be represented as such a mixture if it lies within the bounds of the mixing space. Because the methodology provides a general physical representation of mixed reflectances, it has proven successful for a wide variety of quantitative applications with multispectral imagery (e.g. Adams et al., 1986, 1993; Pech et al., 1986; Smith et al., 1990; Roberts et al., 1998; Elmore et al., 2000; White and Bullard, 2009).

The Alashan mosaic can be represented as a tetrahedral mixing space bounded by four distinct spectral endmembers (Figure 10). The endmembers correspond to green vegetation, non-reflective dark surface and two rock/soil substrates. The non-reflective dark surfaces represent both transmissive (e.g. clear-water), absorptive (e.g. Fe-rich rocks) and non-reflective (e.g. deep-shadow) targets. The rock/soil substrates represent 


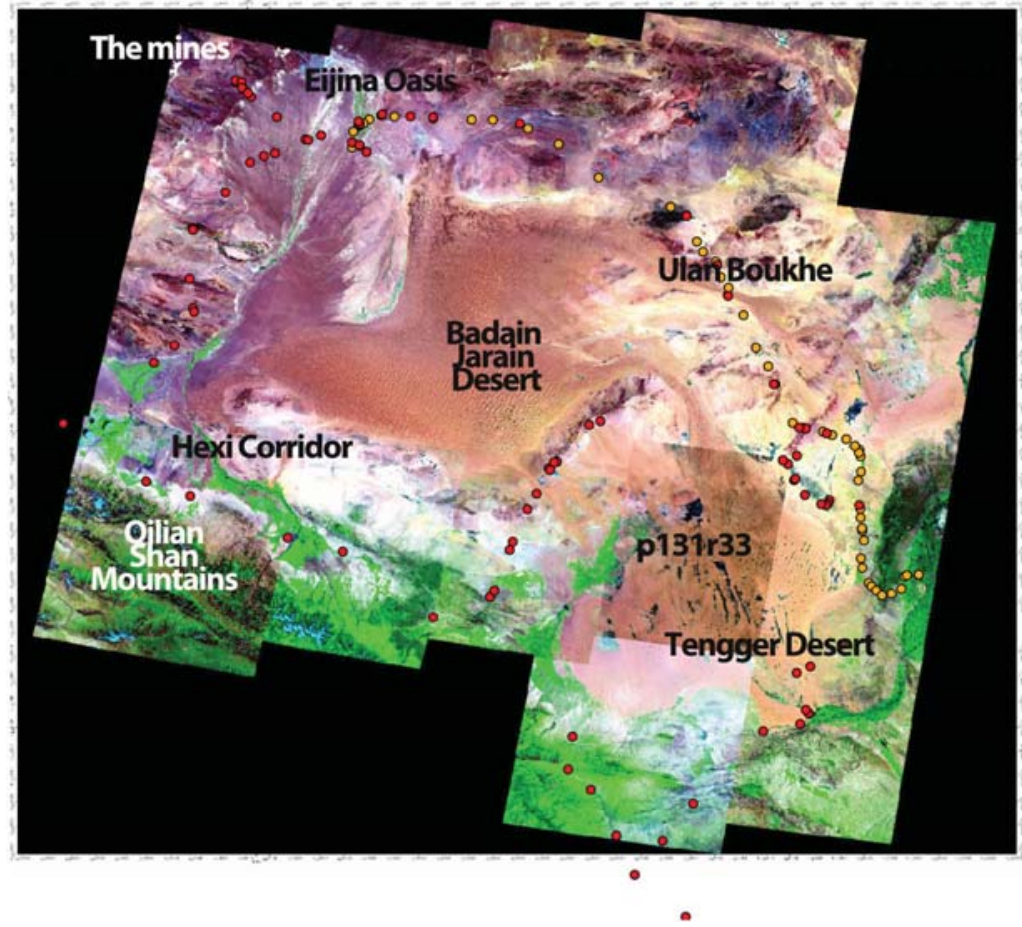

Figure 9. The Alashan study area required a mosaic of 16 ETM + scenes (here RGB colours are associated with bands 7, 4 and 2, respectively). Red and yellow dots (two different GPS used) represent the field validation sites where the samples were taken. This figure is available in colour online at wileyonlinelibrary.com/journal/espl

Table I. Collected Landsat data and acquisition date (day/month/year) for Alashan area. Each scene is distinguished by path and row information; these numbers identify the satellite position during acquisition

\begin{tabular}{cccc}
\hline Path & Row & Landsat 7 ( 2000) & Landsat 7 (2004) \\
\hline 130 & 31 & $22 / 10 / 1999$ & - \\
130 & 32 & $24 / 06 / 2002$ & - \\
130 & 33 & $24 / 06 / 2002$ & $26 / 04 / 2004$ \\
130 & 34 & $24 / 06 / 2002$ & - \\
131 & 31 & $28 / 08 / 2000$ & - \\
131 & 32 & $28 / 08 / 2000$ & - \\
131 & 33 & $14 / 05 / 2002$ & - \\
131 & 34 & $10 / 08 / 1999$ & - \\
132 & 31 & $20 / 09 / 2000$ & - \\
132 & 32 & $20 / 09 / 2000$ & - \\
132 & 33 & $24 / 07 / 2002$ & - \\
133 & 30 & $13 / 10 / 2000$ & $18 / 06 / 2004$ \\
133 & 31 & $28 / 05 / 2002$ & - \\
133 & 32 & $25 / 05 / 2001$ & - \\
133 & 33 & $07 / 07 / 1999$ & - \\
134 & 30 & $23 / 10 / 2001$ & - \\
134 & 31 & $20 / 08 / 2001$ & - \\
134 & 32 & $20 / 08 / 2001$ & - \\
135 & 30 & $26 / 11 / 1999$ & - \\
135 & 31 & $11 / 10 / 2000$ & \\
135 & 32 & $20 / 05 / 2000$ & \\
136 & 30 & $28 / 06 / 2000$ & \\
136 & 31 & $02 / 10 / 2000$ & \\
\hline
\end{tabular}

SWIR bright sands and a higher-albedo, more spectrally flat reflectance corresponding to both evaporates and $\mathrm{mud} / \mathrm{silt}$ lithologies. Following the procedure described in detail by Small (2001, 2004), we generated a mixing space for each individual scene in the Alashan mosaic and a composite mixing space for the entire mosaic. As would be expected, the endmembers derived from the composite mixing space bound those found for each individual scene. However, the selection of three or four endmembers per individual scene resulted in 20 endmember suites (16 scenes + double redundancy for four hotspot scenes) that were generally consistent with the endmembers derived from the regional composite - as well as generic endmembers found in the global analysis described by Small (2004). In addition to the four bounding endmembers for the Alashan composite (red), the generic endmembers (black) and bounding binary mixtures (grey) from the global analysis of Small (2004) are shown. RMS misfits between estimated fractions and observed spectra were generally low $(<0.05$ reflectance units), with no consistent misfit of any major land surface type.

Endmember fraction composites illustrate primary land cover distributions and spatial variations in the areal abundance of the primary biophysical properties of the land surface. Fraction composites are generated by assigning three endmembers to the red, green and blue layers of an image. For Alashan, using one substrate (red), vegetation (green) and dark surface (blue) highlights the agricultural areas and the contrast between highand low-albedo rock/soil substrates (Figure 11a). Using both $\mathrm{mud} / \mathrm{silt}$ (red) and sand (green) as well as dark (blue) highlights lithological differences between the low-albedo Fe-rich crystalline rocks, high-albedo mud/silt deposits and evaporates and intermediate albedo sands (Figure 11b).

\section{Field validation}

Field observations are necessary to calibrate and validate the spectral mixture model and subsequent thematic soil classification. The purpose of the field observations is twofold. First, the field observations allow us to identify the biophysical land cover types and properties associated with the spectral endmembers. Secondly, field reconnaissance allows us to identify significant intermediary land cover types of particular significance. 


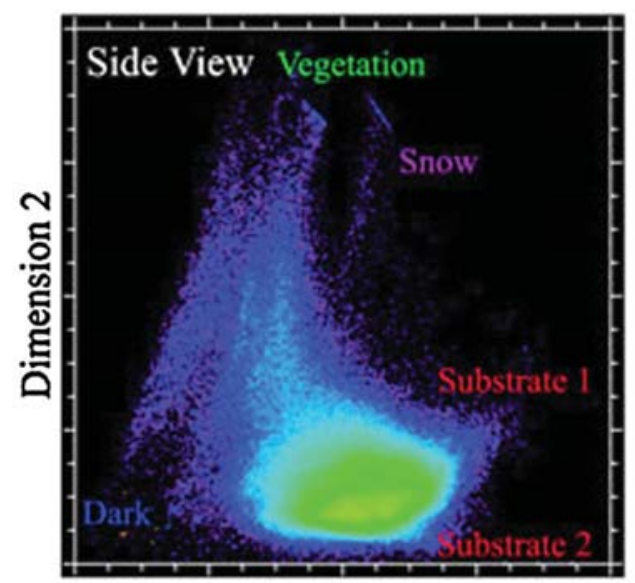

Dimension 1

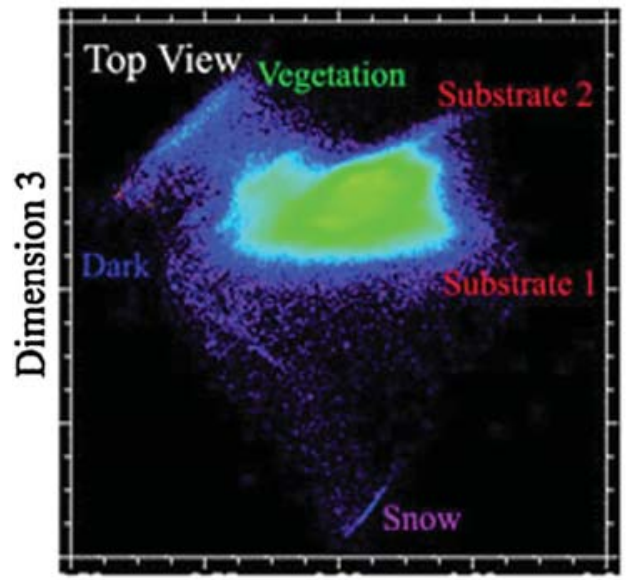

Dimension 1

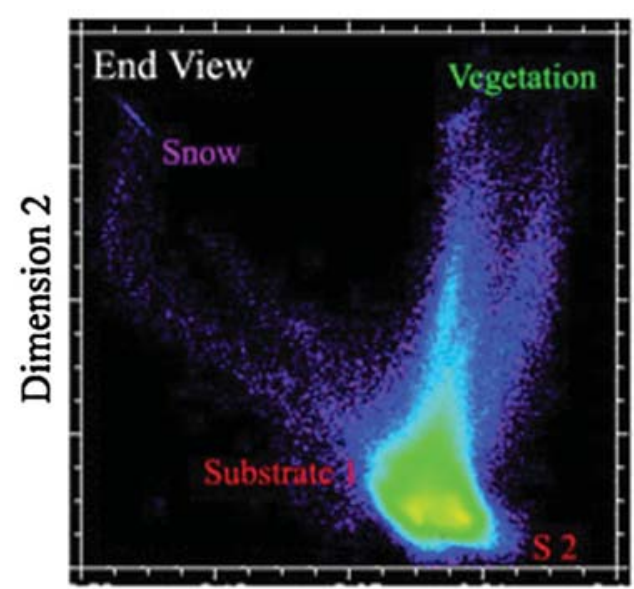

Dimension 3

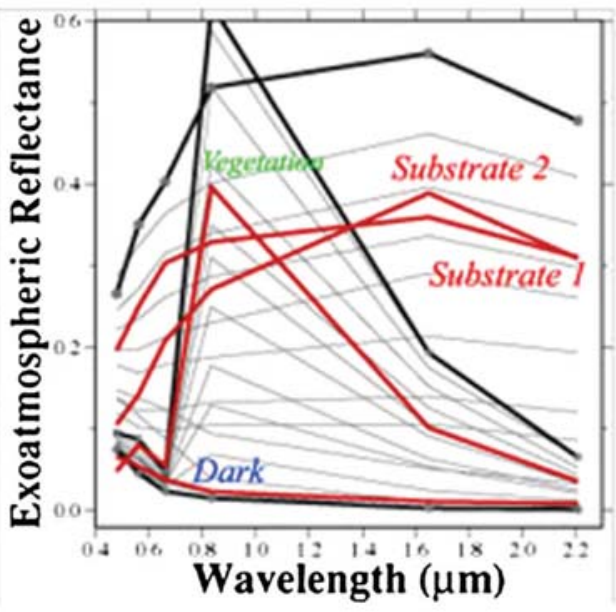

Figure 10. Spectral mixing space for Alashan ETM + mosaic. Colour density shaded (warmer=more pixels) scatter-plots show orthogonal projections of the 3D mixing space spanned by the three low-order principal components (PCs) containing more than $90 \%$ of image variance. Dimension 1 corresponds to rock/ soil substrate fraction, while dimension 2 corresponds to vegetation fraction and dimension 3 accommodates the divergence of substrate 1 (mud/siltstone) and substrate 2 (sand). Snow and ice in the Qilien Shan mountains form a separate mixing continuum not contained within the primary tetrahedral mixing space bounded by the other four endmembers. Binary mixtures from the edges of the mixing space (light grey) are bounded by the composite mixing space endmembers (dark). This figure is available in colour online at wileyonlinelibrary.com/journal/espl

In our field campaign we propose to focus the analysis of reflectance variations mainly on vegetation patterns and soil contents. The surfaces in many hotspots are characterized by sparse or no vegetation cover, with perennial shrubs/bushes and annual and ephemeral plants (e.g. grass, herbs) typical of arid areas. Vegetation is an important controlling factor on dust emission by stabilizing the soil through biophysical feedback (Schlesinger et al., 1990; Lavee et al., 1998) and increasing threshold velocity for wind erosion (Wolfe and Nickling, 1993; Marticorena et al., 2006). The field campaign was designed to provide basic reconnaissance of the region and to sample as many specific soil covers as feasible given the time constraints. Soil samples were collected for each spectral endmember as well as for the most commonly observed substrates found in areas of mixed land cover (Figure 9). The results of the field validation campaign are field photographs, laboratory sample photographs and laboratory reflectance spectra. For each waypoint (CH001 to $\mathrm{CH094}$ ) we collected a GPS location and field photographs of the land cover. At sample points we also collected soil samples and a $1 \mathrm{~m}$ scale sample site photograph. Each sample was separated by size fraction and four reflectance spectra were measured with a 2002 ASD Fieldspec Pro. Samples were illuminated with a LowellPro lamp, Ushio halogen bulb
(JC14.5 V-50WC) and a Lambda DC power supply. Each lab sample was measured four times from opposing azimuths of illumination. Each $5 \mathrm{MP}$ field site and sample images were shot with a 2004 Pentax Optio 555 exposed for neutral balanced histogram (all macrophotographs and reflectance spectra are available on line at: http://www.Ideo.columbia.edu/ small/ Alashan2005/000_SampleSpectra).

Based on the lab sample spectra the presence of three distinct rock/soil substrates and a continuum of Gobi surfaces in the Alashan region were highlighted. Based on that, the unmixing classification has dark endmembers that correspond to Fe-rich crystalline rocks and the other two endmembers, which correspond to sand. Superimposing the reflectance spectra of all the soil samples collected, it is apparent that these soils form a mixing continuum (Figure 11a, b) and that most are intermediate mixtures. To quantify the degree of similarity of the spectra we computed a correlation matrix for all samples (Figure 12a). As shown by the distribution of correlation coefficients, the majority of sample spectra have correlations in excess of 0.8 (Figure 12a). Working on a mixture model for the lab spectra of the Alashan samples it was possible to discuss diagnostic features. Results are shown in Figure 12b, where a principal component analysis was applied on the lab spectra to generate a sparse mixing space. 


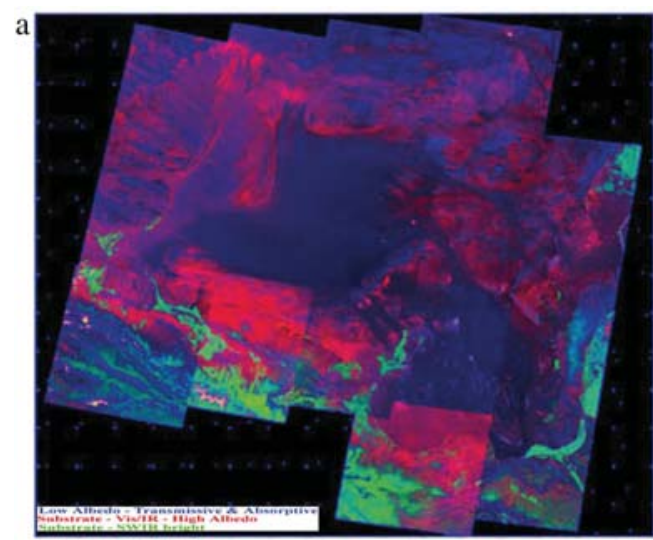

Spectral Endmember Composite $(S I / V / D=R / G / B)$

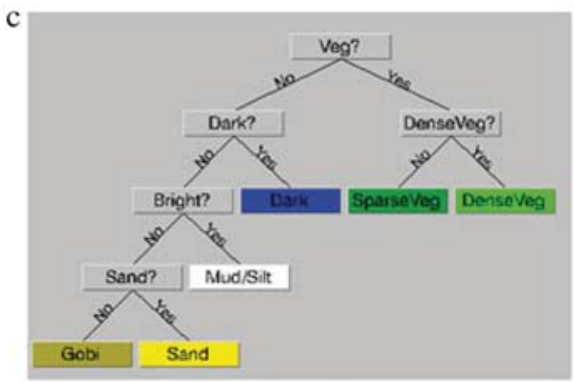

Spectral Endmember Class Decision Tree

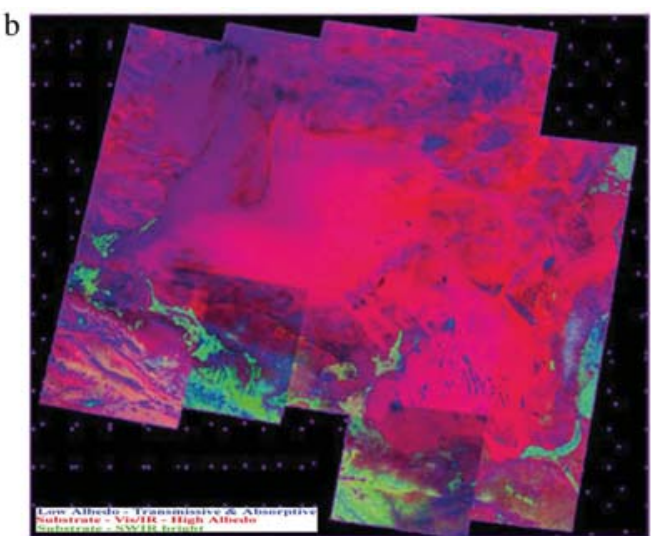

Spectral Endmember Composite $(S 2 / V / D=R / G / B)$

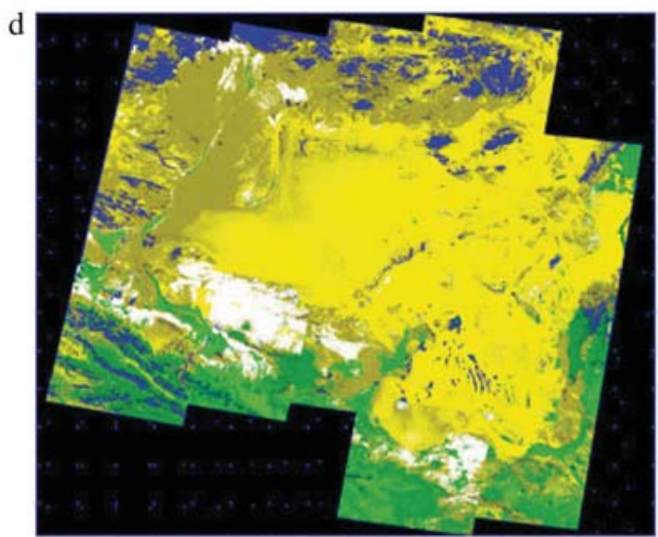

Decision Tree Classification (see tree for classes)

Figure 11. Fraction composites for Alashan are generated by assigning three endmembers to the red, green and blue layers of an image. (a) Using RGB for S1, Vand D, respectively, highlights the agricultural areas and contrast between high- and low-albedo rock/soil substrates. (b) Using RGB for S2, S1 and D, respectively, highlights lithological differences between the low-albedo Fe-rich crystalline rocks, high-albedo mud/silt deposits and evaporites and intermediate albedo sands. The decision tree (c) and spatial distribution of endmember fractions are also shown. D: decision tree classification is shown.

A
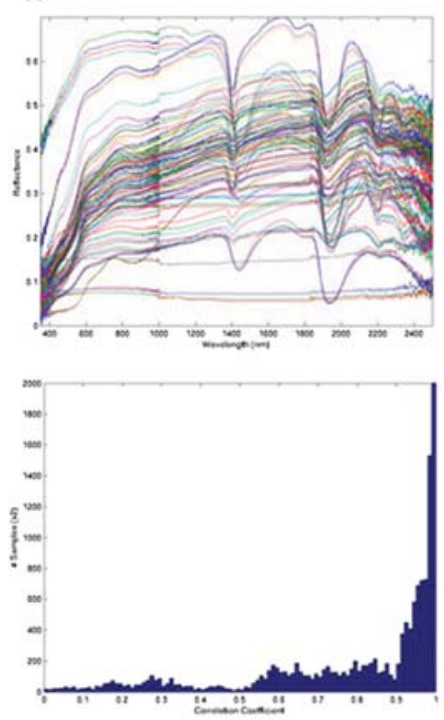
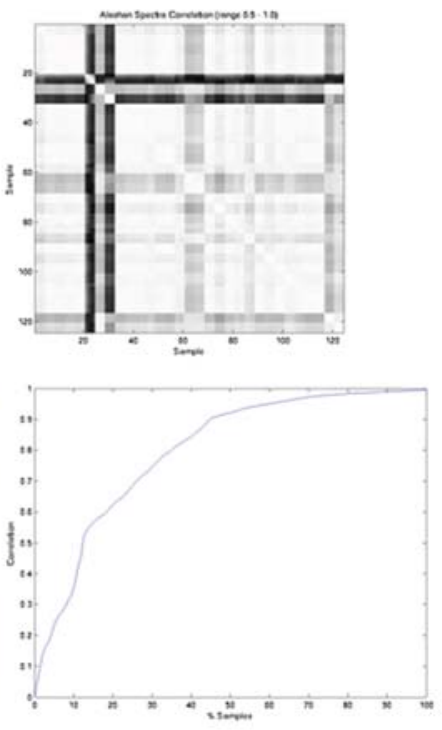

B
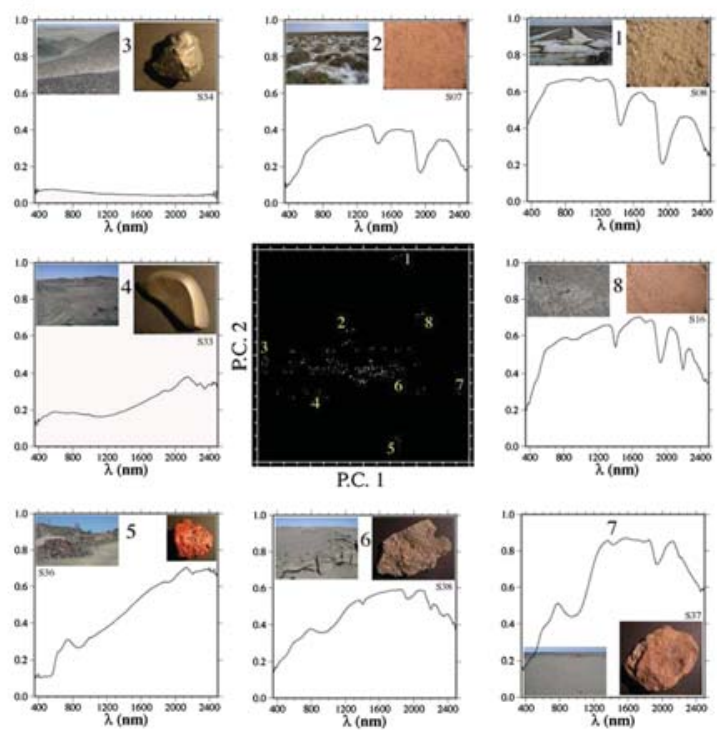

Figure 12. (a) Alashan sample spectra and correlation coefficients. Plot of all soil spectra (top left) shows considerable redundancy within an apparent continuum between the low-albedo moist salt/mud and the high-albedo mud/silt. Nearly flat, very-low-albedo $(<0.1)$ spectra correspond to coal. Correlation matrix (upper right) shows generally high correlations for most of the spectra. Distribution of correlation (lower left) shows at least four modes each corresponding to a spectrum endmember. Cumulative distribution of correlations indicates that $45 \%$ of the spectra have correlation $>0.9$ and are likely linear mixtures of sand and silt. (b) Principal component analysis on the lab spectra to generate a sparse mixing space. 
The central black images show the two primary dimensions of the mixing space (along with some of the bounding spectra and photos of the samples and locations). The primary dimension corresponds to overall albedo, while the second correspond to spectral slope and depth of the SWIR absorptions. The rotations seem to be strongly influenced by the high-amplitude metamorphic spectra (Small et al., 2009). The main result of that is that the most common surface property shown by the unmixing classification is a mixed Gobi surface consisting of poorly sorted silt, sand and pebbles overlain by gravel lag deposits. While the reflectance characteristics of the mixed substrate are similar throughout the Alashan, the lithology of the overlying gravel varies with distance from and composition of the crystalline source rocks within the lacustrine system (confirmed by Fratini et al., 2009, measurements). In fact, contrary to expectation, the uniformly high-albedo endmember picked within the Landsat did not correspond to evaporites in many cases but rather to semi-lithified deposits of a fine-grained mud/siltstone (e.g. $\mathrm{CH052).} \mathrm{On} \mathrm{the} \mathrm{basis} \mathrm{of} \mathrm{the} \mathrm{spectra} \mathrm{(CH054),} \mathrm{laboratory}$ analysis the outcrop deposit corresponds to a shallow lacustrine depositional environment as seen in the field (Figure 13). On the contrary, the evaporite deposits we did find in the field were associated with active salt production ( $\mathrm{CH} 029)$ and were located in areas of elevated water table, so they often appear in the Landsat unmixing classification as mixed low albedo, rather than high albedo as expected and confirmed by literature (Wang et al., 2004b, 2007, and references within). This appears to be the result of a large increase in soil moisture evaluable by the p131r33 Landsat scene, as indicated by its lower albedo and the presence of large bodies of standing water within the dune field that dominate the scene itself. This area is just north of the Yellow River arc-shape region identified in the NDVI variance analysis $\left(39-40^{\circ} \mathrm{N}\right.$ latitude) and is similar within the unmixing classification to the other area that is identified as a long and narrow dust-sand emitting tongue at approximately at $100^{\circ} \mathrm{E}$ longitude and $40-42^{\circ} \mathrm{N}$ latitude (Figure 14), where relict palaeochannels and lacustrine depositional environments were recognized in the field (Figure 15). There are other strandline features where lacustrine silt outcrops over the gravel Gobi surfaces, which are not always visible by SMA analysis, but are identified with the analysis of SAR backscatter data that confirmed the landform interpretation of Gilbert-type deltas within the area (Taramelli, 2011). These landforms are complex, large and well established, implying that alluvial areas and lacustrine depositional environments were stable for extended periods, and that hydrological and climatic conditions were very different in the past (see Fratini et al., 2009, and reference within). Thus, in the lab spectra

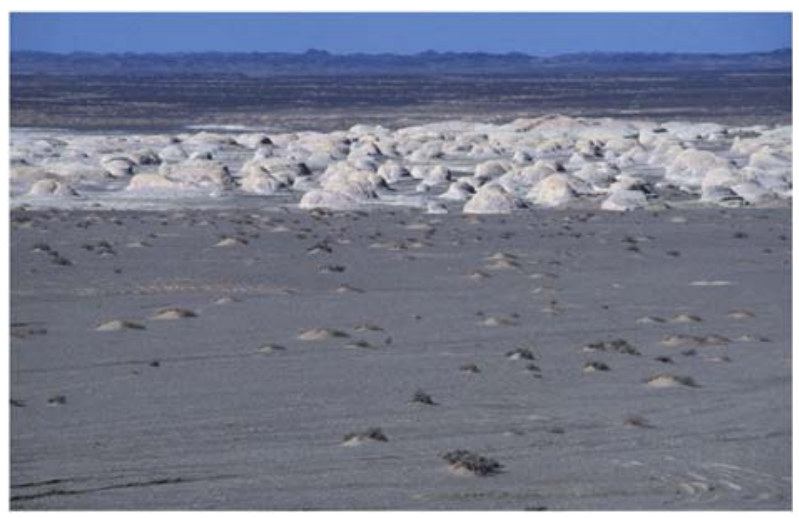

Figure 13. Field site located in the alluvium area in the northwest Gobi (CH044 point location in Figure 14). This figure is available in colour online at wileyonlinelibrary.com/journal/espl analysis and in the subsequent unmixed classification, soil differences between the low-albedo Fe-rich crystalline rocks and the near-horizontal fine- to coarse-grained size are finally evident. Such results lead to the main conclusion that the Alashan soil is characterized by continuously varying land surface properties dominated by rock and soil substrate gradients that need to be classified as Gilbert delta-related soil classes.

Decision tree classification

In addition to calibrating the Landsat spectral mixture model, laboratory analyses complemented the collected in situ spectra (see previous section) in order to extend and quantify land surface properties for soil classification. This was done because discrete soil classes were required for the next phase of the RAMS implementation (Pasqui et al., 2012). We decided to use the decision tree classification to this end. Decision trees provide a more rational approach to soil cover classification than traditional statistical supervised classification. Decision trees allow the user to specify the exact logical basis of class assignment in the form of a Boolean conditional of arbitrary complexity. In other words, decision trees provide a physical basis for which pixels end up in which classes. In the case of Alashan, the mixing spaces show no evidence for feature space clustering but rather show a single heterogeneous cluster representing mixtures of the spectrally distinct endmembers at the apices of the mixing space. The obvious basis for the final soil classification is then endmember abundance. The decision tree can be used to divide the endmember fraction space on the basis of specific abundances of different endmembers (Figure 11c). Starting from the endmembers and working inward to progressively more mixed land covers, the endmember fraction space is successively divided into discrete classes corresponding to specific abundances of each endmember. While this does impose artificial boundaries on a generally continuous land surface, at least the decision boundaries are based on specific physical quantities (areal abundance of endmembers) rather than the maximum of necessarily lowprobability likelihood functions. Once the Landsat imagery has been rendered to a common set of calibrated endmembers, each image was superimposed on the FAO soil classification. Although the FAO soil classification does not accommodate most of the Gobi surfaces found in the Alashan, the general substrate types (mud/silt, sand, Fe-rich crystalline) can be assigned the necessary parameters for the model because they represent distinct biophysical land surface types. Superimposing the different information layers within the decision tree classification identified potential dust-emitting pixels. Textural data were then derived using the FAO global dataset (http://www.fao.org/gtos/tems/index.jsp) with a horizontal resolution of $8 \mathrm{~km}$ (Tegen and Fung, 1994) and eddy covariance measurements (Fratini et al., 2009) within the highlighted endmember pixels (Figure 16). By projecting the bare soil map on to the simulation domain along with the FAO textural map and the land cover derived from MODIS (Bach et al., 2007), the soil characterization table for emitting pixels was obtained (Kjelgaard et al., 2004; Fratini et al., 2009). For each soil type the representative particle radius (grain size classification according to Shepard's, 1954, scheme), particle density and dust productivity were also obtained from the FAO dataset and from Nickovic et al. (2001) (Table II).

The results of spectral mixture analysis indicate that the Alashan region is characterized by continuously varying substrate properties. In addition to the relatively homogeneous sand and mud/silt substrates sampled, there is a wide variety of crystalline rocks cropping out throughout the Alashan region and a widespread Gobi surface of strongly mixed composition. While land cover classes can be specified on the basis of both constant and linear thresholds through the fraction space, the resulting boundaries do not represent the discrete transitions 


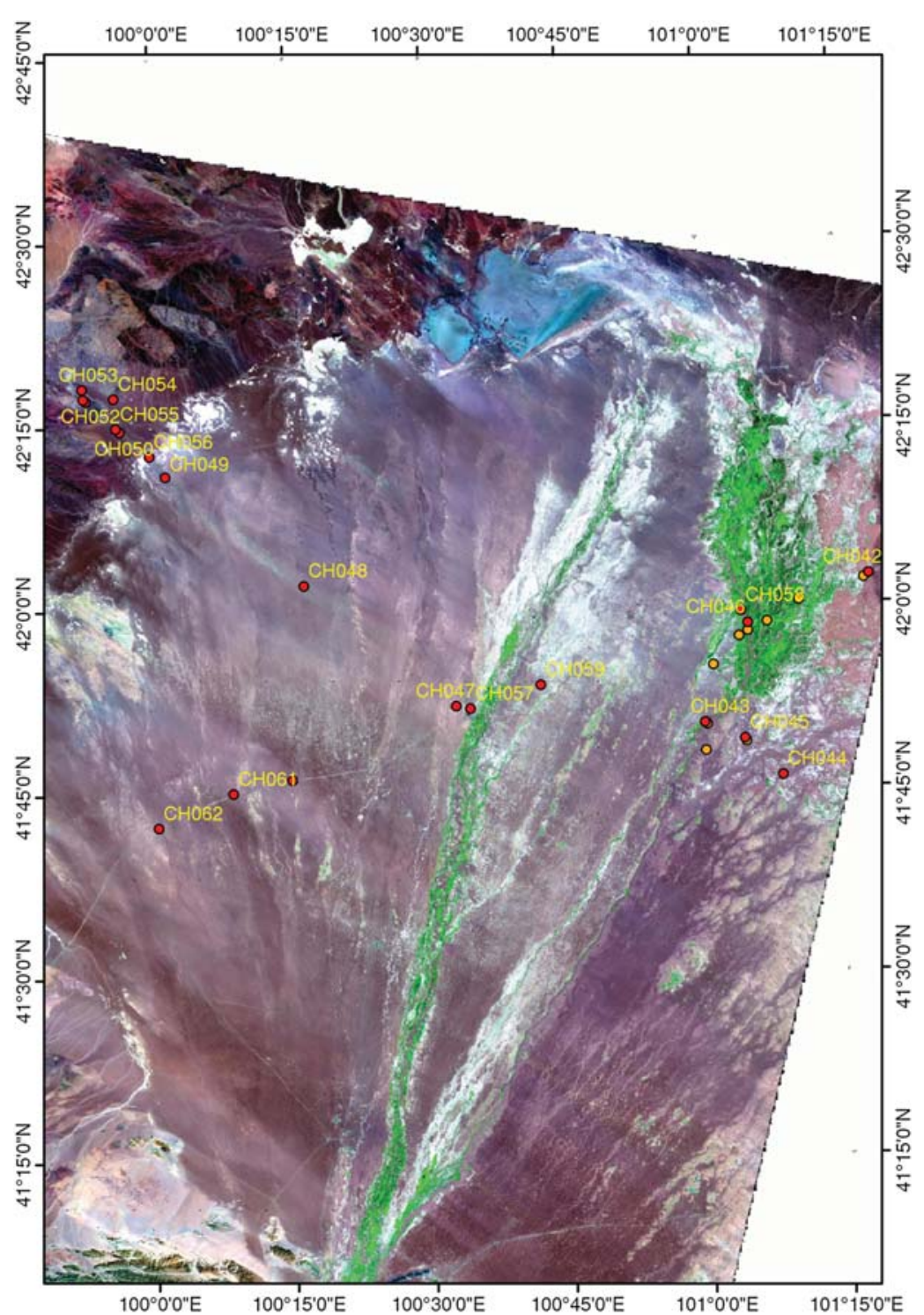

Figure 14. Western Gobi alluvium area. False-colour composite $(\mathrm{R} / \mathrm{G} / \mathrm{B}=7 / 4 / 2)$ from 2001 is dominated by strong contrast between dark, Fe-rich crystalline basement exposure and high-albedo mud/siltstone outcrops and by the alluvial areas (green). Sample stations are represented in red. This figure is available in colour online at wileyonlinelibrary.com/journal/espl

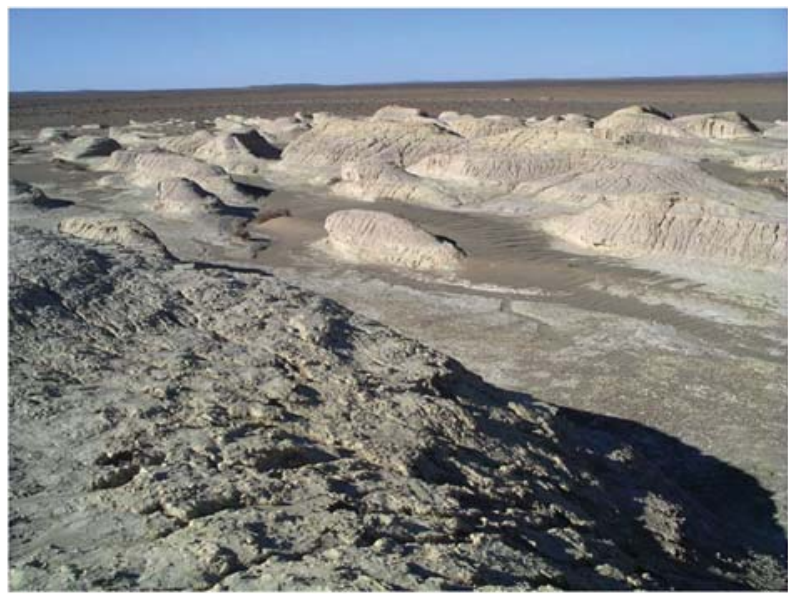

Figure 15. In the field, the lacustrine features appear to be eroded-cut features carved on unconsolidated slope materials or on bedrock in some locations (CH059 point location in Figure 14). This figure is available in colour online at wileyonlinelibrary.com/journal/espl implied by the classification. Where natural boundaries are relatively abrupt (e.g. basement/alluvium contact) the classification will be accurate but where they are gradational the classification will introduce a false boundary. This is especially pronounced on the Gobi surfaces. It is not known what effect these boundaries will have on the dust transport/climate model. However, we feel that the endmember fraction maps do capture many of the physical properties of the land surface and could be used to provide physical properties and boundary conditions directly to the RAMS model - without loss of information and introduction of error inherent in the classification (Pasqui et al., 2012). Potential dust emission sources, although in different locations and of diverse extent, appear to have similar surface composition. In particular, where the SMA results show that dark, Fe-rich crystalline rocks and sand correspond to two of the endmembers it gives robustness to the dust particle physical properties, as seen from Tegen and Fung (1994) and Nickovic et al. (2001). At these highlighted potential emission areas, contrary to expectation, the soils did not correspond to evaporites but to semi-lithified deposits of a fine-grained mud/siltstone. The lacustrine depositional environment features for the Alashan area 


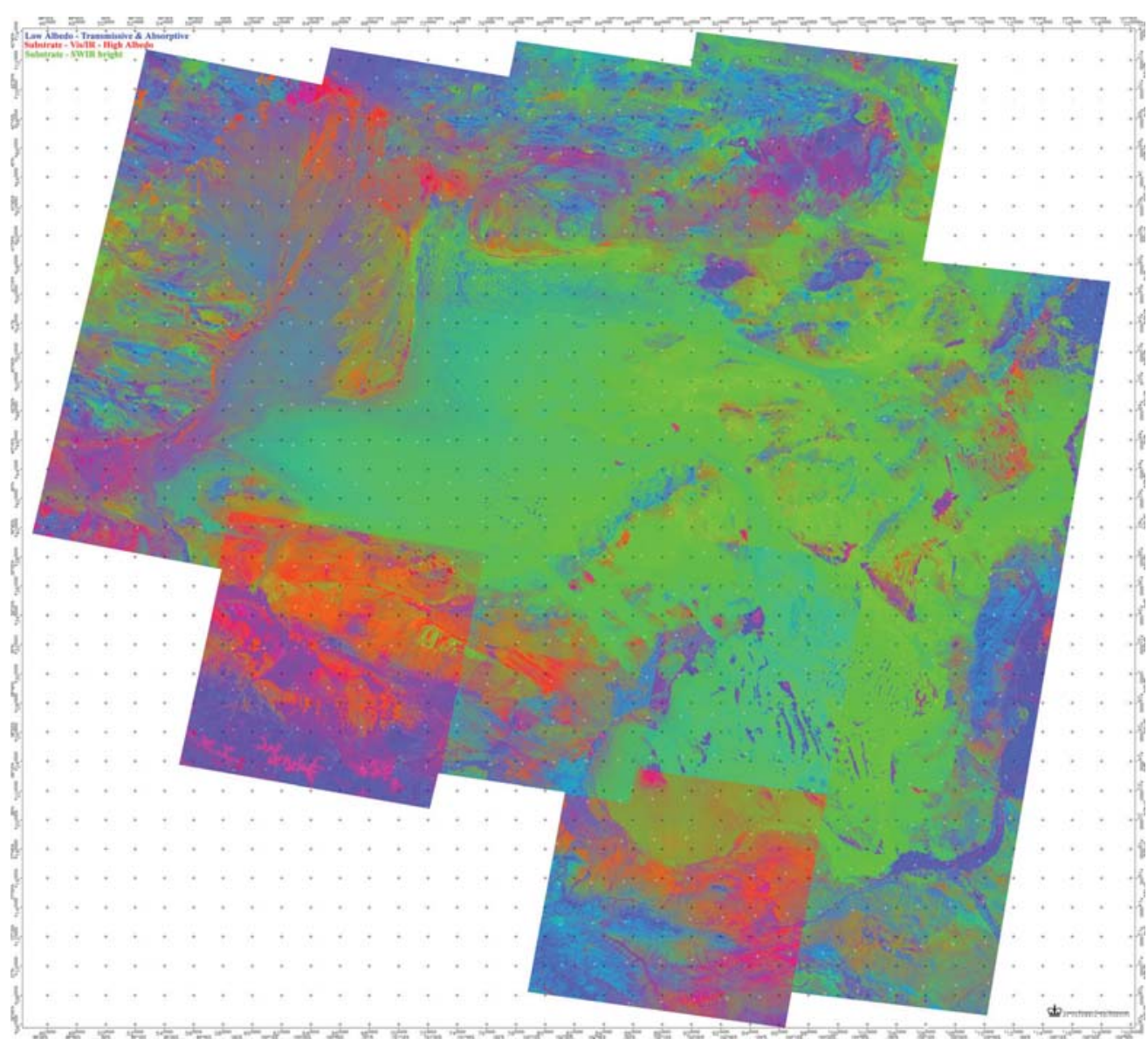

Figure 16. Dust endmembers textural data representation with field sample locations (represented in red). False colour composites $(\mathrm{R} / \mathrm{G} / \mathrm{B}=\mathrm{Vis} / \mathrm{R}-\mathrm{high}$ albedo/SWIR - bright/low albedo) are dominated by strong contrast within the selected endmember and field samples. Differences in non-reflective (blue) endmember fraction likely result from differences in endmember calibration related to different soil moisture between August 2002 and April 2004 images. Road tracks shape file shows the accessible sample site during fieldwork.

Table II. Dust particle physical properties from textural data derived by the FAO global dataset (http://www.fao.org/gtos/tems/index.jsp) with a horizontal resolution of $8 \mathrm{~km}$ (Tegen and Fung, 1994; Nickovic et al., 2001, for dust productivity) parameters and by decision tree land cover classification. Grain size classification according to Shepard's scheme (Shepard, 1954)

\begin{tabular}{lcccc}
\hline Type & Endmembers S1/S2/D classification & Particle radius $(\mu \mathrm{m})$ & Particle density $\left(\mathrm{g} \mathrm{cm}^{-3}\right)$ & Dust productivity \\
\hline Clay & Clay after field validation & 0.73 & 2.50 & 0.08 \\
Silt, small & High-albedo mud/silt & 6.10 & 2.65 & 1.00 \\
Silt, large & intermediate-albedo Sands & 18.00 & 2.65 & 1.00 \\
Sand & Sand & 38.00 & 2.65 & 0.12 \\
\hline
\end{tabular}

represent a potential high-emission area, especially where the alluvium meets the crystalline basement.

\section{Discussion}

For Alashan, the outstanding questions involved the composition of several mixed reflectance signatures and the presence and abundance of sparse vegetation. A more complete representation of the variety of different substrate types was necessary to isolate potential dust source regions. In order to monitor progressive degradation of the land cover (by grazing and salt formation) a specific effort to quantify and map spatiotemporal changes in sparse vegetation abundance was implemented. This study found that regional vegetation change can be effectively evaluated through the use of coarse-resolution AVHRR NDVI, producing variance measurements of NDVI from 1981 to 2003. Regions that we observe as having a waning vegetation signal could either be due to natural large-scale climatological fluctuations from changes in precipitation or from agricultural impact (see the related phonological-meteorological study in Lee et al., 2002). While at present these regions may not serve as significant sources for dust emission, they could be problematic in the future (Zeng et al., 2005; Baddock et al., 2009). These regions could generate more immediate local affects such as environmental degradation and air-quality deterioration as already seen in the literature (Yu et al., 1999). In addition, the proposed multi-temporal analysis of NDVI changes has highlighted land 
cover degradation validated by the SMA analysis that could result in new potential source regions. Diagnostic spectral features in the Landsat spectral range made it possible to use SMA to retrieve information related to surface materials. Pixels that are potential dust sources were highlighted by SMA in the absence of field data usually utilized in modelling dust studies (saltating particles, streamwise saltation flux, minimally and fully dispersed particle size distributions - Gillespie, 1992; Crowley and Hook, 1996; Ramsey et al., 1999; Rowan and Mars, 2003; Katra and Lancaster, 2008). Based on the fieldwork done in order to validate the Landsat classification, a more complete representation of the variety of different substrate types is used to isolate potential dust source regions within the lacustrine areas. This classification shows that an increasing sparse vegetation trend is the confirming evidence of specific dust source areas with literature data (Wang et al., 2004a). Loss of vegetation has been identified as a primary focus of their degradation monitoring activities, especially related to the NDVI trend. In addition to its effect on dust generation, vegetation degradation also affects soil erosion and the livelihoods of the pastoralists living in the Alashan region. Fortunately, spectral mixture analysis is well suited to monitoring vegetation health and abundance (Small and Lu, 2006), particularly in arid and semiarid environments (Elmore et al., 2000). Mapping at-sensor radiances into endmember fraction abundances converts a physical measure of reflected solar radiance to a physically meaningful estimate of a basic biophysical property of the land surface. As such, endmember fraction maps could provide an ideal input to climate models, vastly superior to the thematic classifications normally used. The advantages of endmember fraction abundances are: (1) physically meaningful quantities (e.g. vegetation fraction, albedo); (2) greater accuracy; (3) no loss of spatial variability information; (4) no introduction of error from class homogenization; and (5) no errors of commission or omission (Small, 2006). The parametrization of the dust source model input parameters has been established through the RAMS procedure (Pasqui et al., 2012). From the RAMS model, the area producing the highest amount of dust is located in the southern part of Alashan Prefecture, between $103^{\circ}$ and $106^{\circ}$ E longitude. Moreover, a long and narrow dust-sand-emitting tongue at approximately $100^{\circ} \mathrm{E}$ longitude and $40-42^{\circ} \mathrm{N}$ latitude was confirmed by the RAMS model using remote sensing inputs (Figure 6 in Pasqui et al., 2012).

The work done so far provides a good foundation for an intensive spatiotemporal monitoring programme for the Alashan region that could be used within the emission-transport modelling system. The combined remote sensing and modelling approach could be used for long-term simulations and it should be considered as a potential monitoring tool in an integrated management to dust storm source area identification and control. The multi-scale remote sensing approach, in fact, represents a practical tool for building possible scenarios both for small- and large-scale areas. This could also provide quantitative evaluation of the effects produced by the different human activities adopted on the potential emission areas, leading to a more systematically integrated monitoring system.

\section{Conclusion}

Advanced remote sensing was used, in association with filed sampling, to identify potential dust sources on the basis of vegetation cover and surface sediment characteristics. The methodology is useful for developing an extensive multi-source and multi-temporal analysis and, as a result, helping to identify the baseline environmental conditions necessary to detect changes to potential dust sources at regional and local scales in northern China. A key aspect of the study is characterizing the spatial distribution of surface properties at high resolution in dust emission hotspot regions and identifying the response of these surfaces to changes in climate and land cover/use, since the exposed surface sediments determine the dust composition. Results provide a baseline on which to discriminate land cover for mapping potential dust source regions and to generate inputs to the regional model (RAMS).

The strategy of combining low- and moderate-resolution remote sensing with fieldwork validation highlights different hotspot areas where a combination of low topography, depositional processes, loose/salty soil and sparse/free vegetation act as the main driving factors of dust emission. The approach accounted for previous knowledge of relationships between landforms and dust emissions in northwest China (Ding et al., 2005). Dust sources in this study were analysed jointly with the areas surrounding them (NDVI analysis), allowing for a better understanding of surface processes. While the major sources of dust occur in extremely arid regions, such as dune fields in the Alashan, which have little to no vegetation throughout the year, areas with a decreasing NDVI signal may also become potential dust sources in the future as highlighted by the SMA. The remote modelling approach shown in this study could be used for longterm dust source identification and it should be considered as a potential monitoring tool in an integrated management approach to dust source control.

Acknowledgements - The present work was developed in the framework of the WINDUST project, established and funded in 2004 by the Italian Ministry of Environment and the Beijing Municipality Environmental Protection Bureau, with the aim of studying formation of the dust sandstorms affecting Beijing and proposing mitigation actions. Acknowledgement and thanks go to the Beijing Environmental Protection Foundation for supervision of the activities conducted in China, and to all the Beijing EPB technical staff for their valuable suggestions and collaboration. Special thanks go also to Professor Wang Tao and Dr Sun Qingwei of the Cold and Arid Regions Environmental and Engineering Research Institute (CAREERI) of the Chinese Academy of Science for their scientific contribution and fundamental assistance during fieldwork in the Alashan region. Special thanks to Dr G. Giuliani and Dr S. Melani for their help and support in setting up the modelling system, to Dr Monia Santini for giving us some of the field samples in the Tengger and Eijna areas and for her valuable suggestions in the manuscript preparation, and to $\mathrm{Dr} \mathrm{L}$. Torriano and Ing. P. Scalas for their help and efforts during the project. We also thank Dr M. Cremonini, Dr M. Martinelli, Professor G. Maracchi and Professor J. K. Weissel for their support in all our activities. The authors also wish to thank the anonymous reviewers and associated editors for their helpful comments, which improved the quality of the original manuscript.

\section{References}

Adams JB, Smith MO, Gillespie AR. 1993. Imaging spectroscopy: interpretation based on spectral mixture analysis. In Remote Geochemical Analysis: Elemental and Mineralogical Composition, Pieters CM, Englert P (eds). Cambridge University Press: New York; 145-166.

Adams JB, Smith MO, Johnson PE. 1986. Spectral mixture modeling: a new analysis of rock and soil types at the Viking Lander 1 site. Journal of Geophysical Research 91: 8098-8122.

Bach D, Barbour J, Macchiavello G, Martinelli M, Scalas P, Small C, Stark C, Taramelli A, Torriano L, Weissel J. 2007. Integration of the advanced remote sensing technologies to investigate the dust storm areas. In Human and Nature: Working Tighter for Sustainable Development of Drylands. Proceedings of 8th ICDD Conference, El-Beltagy A, Saxena MC, Wang T (eds), 25-28 February 2006, Beijing. ICARDA, Aleppo, Syria; 387-397.

Baddock M, Bullard JE, Bryant RG. 2009. Dust source identification using MODIS: a comparison of techniques applied to the Lake Eyre Basin, Australia. Remote Sensing of Environment 113: 1511-1528.

Boardman JW. 1993. Automating spectral unmixing of AVIRIS data using convex geometry concepts. In Fourth airborne visible/infrared 
imaging spectrometer (AVIRIS) airborne geoscience workshop, Green RO (ed.).CA Jet Propulsion Laboratory: Pasadena; 11-14.

Boardman JW, Kruse FA. 1994. Automated spectral analysis: A geologic example using AVIRIS data, north Grapevine mountains, Nevada. Tenth Thematic Conference on Geologic Remote Sensing. Environmental Research Institute of Michigan: Ann Arbor, MI; 1407-1418.

Bryant RG, Bigg RR, Mahowald NM, Eckardt FD, Ross SG. 2007. Dust emission response to climate in southern Africa. Journal of Geophysical Research D: Atmospheres 112: 1-17.

Bullard JE, Baddock M, McTainish G, Leys J. 2008. Sub-basin scale dust source geomorphology detected using MODIS. Geophysical Research Letters 35: L15404.

Bullard JE, Harrison SP, Baddock MC, Drake N, Gill TE, McTainsh G, Sun Y. 2011. Preferential dust sources: a geomorphological classification designed for use in global dust-cycle models. Journal of Geophysical Research 116: F04034.

Chander G, Markham BL, Helder DL. 2009. Summary of current radiometric calibration coefficients for Landsat MSS, TM, ETM+, and EO-1 ALI sensors. Remote Sensing of Environment 113(2009): 893-903, doi:10.1016/j.rse.2009.01.007

Chladil MA, Nunez M. 1995. Assessing grassland moisture and biomass in Tasmania-the application of remote-sensing and empirical-models for a cloudy environment. International Journal of Wildland Fire 5: 165-171.

Crowley JK, Hook SJ. 1996. Mapping playa evaporite minerals and associated sediments in Death Valley, CA, with multispectral thermal infrared images. Journal of Geophysical Research 101: 643-660.

Ding R, Li J, Wang S, Ren F. 2005. Decadal change of the spring dust storm in northwest China and the associated atmospheric circulation. Geophysical Research Letters 32: L02808.

Elmore AJ, Mustard JF, Manning SJ, Lobell DB. 2000. Quantifying vegetation change in semiarid environments: precision and accuracy of spectral mixture analysis and the normalized difference vegetation index. Remote Sensing of Environment 73: 87-102.

Elvidge CD, Baugh KE, Kihn EA, Kroehl HW, Davis ER. 1997a. Mapping of city lights using DMSP Operational Linescan System data. Photogrammetric Engineering and Remote Sensing 63: 727-734.

Elvidge CD, Baugh KE, Kihn EA, Kroehl HW, Davis ER, Davis C. 1997b. Relation between satellite observed visible: near infrared emissions, population, and energy consumption. International Journal of Remote Sensing 18: 1373-1379.

Engelstaedter S, Kohfeld KE, Tegen I, Harrison SP. 2003. Controls of dust emissions by vegetation and topographic depressions: an evaluation using dust storm frequency data. Geophysical Research Letters 30: 1294-1298.

Fratini G, Ciccioli P, Febo A, Forgione A, Valentini R. 2007. Size-segregated fluxes of mineral dust from a desert area of northern China by eddy covariance. Atmospheric Chemistry and Physics 7: 2839-2854.

Fratini G, Da Canal S, Valentini R. 2005. Dust storms and rural development in north China. Know Risk, Tudor R (ed.). For UNCCD World Conference on Disaster Reduction; 254-256.

Fratini G, Santini M, Ciccioli P, Valentini R. 2009. Evaluation of a wind erosion model in a desert area of northern Asia by eddy covariance. Earth Surface Processes and Landforms 34: 1743-1757.

Gillespie A. 1992. Spectral mixture analysis of multispectral thermal infrared images. Remote Sensing of Environment 42: 137-145.

Gillespie AR, Smith MO, Adams JB, Willis SC, Fischer AF, Sabol DE. 1990. Interpretation of residual images: spectral mixture analysis of AVIRIS images, Owens Valley, California. In Proceedings of the 2nd Airborne Visible/Infrared Imaging Spectrometer (AVIRIS) Workshop, NASA Jet Propulsion Laboratory, Pasadena, CA; 243-270.

Gillette DA. 1999. A qualitative geophysical explanation for 'hot spot' dust emitting source regions. Contributions to Atmospheric Physics 72: $67-77$.

Ginoux P, Chin M, Tegen I, Prospero J, Holben B, Dubovik O, Lin SJ. 2001. Sources and distributions of dust aerosols simulated with the GOCART model. Journal of Geophysical Research 106: 20255-20273.

Goudie AS, Middleton NJ. 2001. Saharan dust storms: nature and consequences. Earth-Science Reviews 56: 179-204.

Israelevich P, Levin Z, Joseph J, Ganor E. 2002. Desert aerosol transport in the Mediterranean Region as inferred from the TOMS aerosol index. Journal of Geophysical Research-Atmospheres 107(D21): no. 4572.

Johnson PE, Smith MO, Taylor-George S, Adams JB. 1983. A semiempirical method for analysis of the reflectance spectra for binary mineral mixtures. Journal of Geophysical Research 88: 3557-3561. de Jong R, de Bruin S, de Wit A, Schaepman ME, Dent DL. 2011. Analysis of monotonic greening and browning trends from global NDVI timeseries. Remote Sensing of Environment 115: 692-702.

Katra I, Lancaster N. 2008. Surface-sediment dynamics in a dust source from spaceborne multispectral thermal infrared data. Remote Sensing of Environment 112: 3212-3221.

Kaufman YJ, Koren I, Remer LA, Tanre D, Ginoux P, Fan S. 2005. Dust transport and deposition observed from the Terra-Moderate Resolution Imaging Spectroradiometer (MODIS) spacecraft over the Atlantic Ocean. Journal of Geophysical Research 110: D10S12.

Kawabata A, Ichii K, Yamaguchi Y. 2001. Global monitoring of interannual changes in vegetation activities using NDVI and its relationships to temperature and precipitation. International Journal of Remote Sensing 22: 1377-1382.

Kjelgaard JF, Chandler DG, Saxton KE. 2004. Evidence for direct suspension of loessial soils on the Columbia Plateau. Earth Surface Processes and Landforms 29: 221-236.

Lavee H, Imeson AC, Pariente S. 1998. The impact of climate change on geomorphology and desertification along a Mediterranean-arid transect. Land Degradation and Development 9: 407-422.

Lee JA, Gill TE, Mulligan KR, Acosta MD, Perez AE. 2009. Land use/ land cover and point sources of the 15 December 2003 dust storm in Southwestern North America. Geomorphology 105: 18-27.

Lee R, Yu F, Price KP, Ellis J, Shi P. 2002. Evaluating vegetation phonological patterns in Inner Mongolia using NDVI time-series analysis. International Journal of Remote Sensing 23: 2505-2512.

Legrand M, Plana-Fattori A, N'doume C. 2001. Satellite detection of dust using the IR imagery of Meteosat: 1. Infrared difference dust index. Journal of Geophysical Research 106(D16): 18251-18274.

Mahowald N, Luo C, del Corral J, Zender C. 2003. Interannual variability in atmospheric mineral aerosols from a 22 -year model simulation and observational data. Journal of Geophysical Research 108: 4352-4371.

Malo AR, Nicholson SE. 1990. A study of the rainfall and vegetation dynamics in the African Sahel using the normalized difference vegetation index. Journal of Arid Environments 19: 1-24.

Marticorena B, Kardous M, Bergametti G, Callot Y, Chazette P, Khatteli H, Le Hégarat-Mascle S, Maillé M, Rajot JL, Vidal-Madjar D, Zribi M. 2006. Surface and aerodynamic roughness in arid and semiarid areas and their relation to radar backscatter coefficient. Journal of Geophysical Research 111: F03017.

Maselli F, Conese C, Petkov L, Gilabert MA. 1993. Environmental monitoring and crop forecasting in the Sahel through the use of NOAA NDVI data. A case study: Niger 1986-1989. International Journal of Remote Sensing 14: 3471-3487.

Meloni D, di Sarra A, Di lorio T, Fiocco G. 2004. Direct radiative forcing of Saharan dust in the Mediterranean from measurements at Lampedusa Island and MISR space-borne observations. Journal of Geophysical Research 109: D08206.

Miller RL, Cakmur RV, Perlwitz J, Geogdzhayev IV, Ginoux P, Koch D, Kohfeld KE, Prigent C, Ruedy R, Schmidt GA, Tegen I. 2006. Mineral dust aerosols in the NASA Goddard Institute for Space Sciences ModelE atmospheric general circulation model. Journal of Geophysical Research 111: D06208.

Nicholson SE, Farrar TJ. 1994. The influence of soil type on the relationship between NDVI, rainfall, and soil moisture in semiarid Botswana: I. NDVI response to rainfall. Remote Sensing of Environment 50: 107-120.

Nicholson SE, Davenport ML, Malo AR. 1990. A comparison of the vegetation response to rainfall in the Sahel and East Africa, using NDVI from NOAA AVHRR. Climatic Change 17: 209-241.

Nickovic S, Kallos G, Papadopoulos A, Kakaliagou O. 2001. A model for prediction of desert dust cycle in the atmosphere. Journal of Geophysical Research 106: 18113-18129.

Okin GS, Bullard JE, Reynolds RL, Ballantine J-AC, Schepanski K, Todd MC, Belnap J, Baddock MC, Gill TE, Miller ME. 2011. Dust: small-scale processes with global consequences. Eos 92: 241-242.

Okin GS, Gillette DA, Herrick JE. 2006. Multi-scale controls on and consequences of aeolian processes in landscape change in arid and semi-arid environments. Journal of Arid Environments 65: 253-275.

Pasqui M, Taramelli A, Barbour J, Kirschbaum D, Bottai L, Busillo C, Calastrini F, Gualtieri G, Guarnieri F, Small C. 2012. Dust emission in Northern China: atmospheric emission: dispersion modelling of a major dust event. Earth Surface Processes and Landforms (in review). 
Pech RP, Davies AW, Lamacraft RR, Graetz RD. 1986. Calibration of Landsat data for sparsely vegetated semi-arid rangelands. International Journal of Remote Sensing 7: 1729-1750.

Peters AJ, Eve MD, Holt EH, Whitford WG. 1997. Analysis of desert plant community response to moisture availability. Environmental Monitoring and Assessment 37: 273-287.

Prospero JM, Ginoux P, Torres O, Nicholson SE, Gill TE. 2002. Environmental characterisation of global sources of atmospheric soil dust identified with the Nimbus 7 total ozone mapping spectrometer (TOMS) absorbing aerosol product. Reviews of Geophysics 40: 1002.

Qian W, Quan L, Shi S. 2002. Variations of the dust storm in China and its climatic control. Journal of Climate 15: 1216-1229.

Ramsey MS, Christensen PR, Lancaster N, Howard DA. 1999. Identification of sand sources and transport pathways at the Kelso Dunes, California using thermal infrared remote sensing. Geological Society of America Bulletin 111: 646-662.

Reheis MC, Kihl R. 1995. Dust deposition in southern Nevada and California, 1984-1989: relations to climate, source area, and source lithology. Journal of Geophysical Research 100(D5): 8893-8918.

Reynolds RL, Yount YC, Reheis M, Goldstein H, Chavez P Jr, Fulton R, Whitney J, Fuller C, Forester RM. 2007. Dust emissions from wet and dry playas in the Mojave Desert, USA. Earth Surface Processes and Landforms 32: 1811-1827.

Rivera Rivera NI, Gill TE, Gebhart KA, Hand JL, Bleiweiss MP, Fitzgerald RM. 2009. Wind modeling of Chihuahuan Desert dust outbreaks. Atmospheric Environment 43: 347-354.

Roberts DA, Batista G, Pereira J, Waller E, Nelson B. 1998. Change Identification using Multitemporal Spectral Mixture Analysis: applications in eastern Amazonia. In Remote Sensing Change Detection: Environmental Monitoring Applications and Methods, Elvidge C, Lunetta R (eds). CRC Press: Ann Arbor, MI; 137-161.

Rowan LC, Mars JC. 2003. Lithologic mapping in the Mountain Pass, California area using Advanced Spaceborne Thermal Emission and Reflection Radiometer (ASTER) data. Remote Sensing of Environment 84: 350-366.

Sabol DE, Adams JB, Smith MO. 1992. Quantitative sub-pixel spectral detection of targets in multispectral images. Journal of Geophysical Research 97: 2659-2672.

Santini M, Taramelli A, Sorichetta A. 2010. Algorithm to calculate equalarea on a latitude-longitude (geographic) regular grid. Transactions in GIS 14: 351-377.

Scheidt S, Ramsey M, Lancaster N. 2007. Radiometric normalization and image mosaic generation of ASTER thermal infrared data: an application to extensive sand sheets and dune fields. Remote Sensing of Environment 112: 920-933.

Schepanski K, Tegen I, Laurent B, Heinold B, Macke A. 2007. A new Saharan dust source activation frequency map derived from MSG-SEVIR IR-channels. Geophysical Research Letters 34: L18803.

Schlesinger WH, Fonteyn PJ, Marion GM, Reiners WA. 1990. Biological feedbacks in global desertification. Science 247: 1043-1048.

Schmidt H, Karnieli A. 2000. Remote sensing of the seasonal variability of vegetation in a semi-arid environment. Journal of Arid Environment 45: 43-59.

Settle JJ, Drake NA. 1993. Linear mixing and the estimation of ground cover proportions. International Journal of Remote Sensing 14: 1159-1177.

Shepard FP. 1954. Nomenclature based on sand-silt-clay ratios. Journal of Sedimentary Research 24: 151-158.

Singer RB. 1981. Near-infrared spectral reflectance of mineral mixtures: systematic combinations of pyroxenes, olivine and iron oxides. Journal of Geophysical Research 86: 7967-7982.

Singer RB, McCord TB. 1979. Mars: large scale mixing of bright and dark surface materials and implications for analysis of spectral reflectance. In 10th Lunar and Planetary Science Conference, American Geophysical Union, Washington, DC; 1835-1848.

Small C. 2001. Estimation of urban vegetation abundance by spectral mixture analysis. International Journal of Remote Sensing 22: 1305-1334.

Small C. 2004. The Landsat ETM+Spectral Mixing Space. Remote Sensing of Environment 93: 1-17.

Small C. 2006. Comparative analysis of urban reflectance and surface temperature. Remote Sensing of Environment 104: 168-189.
Small C, Lu JWT. 2006. Estimation and vicarious validation of urban vegetation abundance by spectral mixing analysis. Remote Sensing of Environment 100: 441-456.

Small C, Steckler M, Seeber N, Imam B, Akhter H, Bodruddoza M, Goodbred S. 2009. Spectroscopy of sediments in the Ganges Brahmaputra delta: spectral effects of moisture and grain size. Remote Sensing of Environment 13: 342-361.

Smith MO, Ustin SL, Adams JB, Gillespie AR. 1990. Vegetation in deserts: I. A regional measure of abundance from multispectral images. Remote Sensing of Environment 31: 1-26.

Taramelli A. 2011. Detecting landforms using quantitative radar roughness characterization and spectral mixing analysis. In Geocomputation, Sustainability and Environmental Planning, Murgante B, Borruso G, Lapucci A (eds). Studies in Computational Intelligence 348, Springer: Berlin; 225-249.

Taramelli A, Melelli L. 2009. Map of deep seated gravitational slope deformation susceptibility in central Italy derived from SRTM DEM and spectral mixing analysis of the Landsat ETM + data. International Journal of Remote Sensing 30: 357-387.

Tegen I, Fung I. 1994. Modeling of mineral dust in the atmosphere: Sources, transport, and optical thickness. Journal of Geophysical Research 99(D11): 22897-22914.

Tegen I, Harrison SP, Kohfeld KE, Prentice IC, Coe MT, Heimann M. 2002. The impact of vegetation and preferential source areas on global dust aerosol: Results from a model study. Journal of Geophysical Research 107: 4576-4597.

Todd MC, Martins V, Washington R, Lizcano G, Mbainayel S, Engelstaedter S. 2007. Mineral dust emission from the Bodélé Depression, northern Chad, during BoDEx 2005. Journal of Geophysical ResearchAtmospheres 112(D6): D06207.

Townshend JRG, Justice CO. 1986. Analysis of dynamics of African vegetation using the NDVI. International Journal of Remote Sensing 7: 1224-1242.

Tucker CJ, Newcomb WW, Dregne HE. 1994. AVHRR data sets for determination of desert spatial extent. International Journal of Remote Sensing 17: 3517-3565.

Tucker CJ, Newcomb WW, Los SO, Prince SD. 1991. Mean and interyear variation of growing-season normalized difference vegetation index for the Sahel 1981-1989. International Journal of Remote Sensing 12: 1113-1115.

Tucker CJ, Pinzon JE, Brown ME. 2004. Global Inventory Modeling and Mapping Studies (GIMMS) Satellite Drift Corrected and NOAA-16 incorporated Normalized Difference Vegetation Index (NDVI), Monthly 1981-2002. University of Maryland.

Tucker CJ, Pinzon JE, Brown ME, Slayback DA, Pak EW, Mahoney R, Vermote EF, el Saleous N. 2005. An extended AVHRR 8-km NDVI dataset compatible with MODIS and SPOT vegetation NDVI data. International Journal of Remote Sensing 26: 4485-4498.

Urban FE, Reynolds RL, Fulton R. 2009. The dynamic interaction of climate, vegetation, and dust emission, Mojave Desert, USA. In Arid Environments and Wind Erosion, Fernandez-Bernal A, De la Rosa MA (eds). Nova Science: Hauppauge, NY; 243-267.

Valor E, Caselles V. 1996. Mapping land surface emissivity from NDVI: Application to European, African, and South American areas. Remote Sensing of Environment 57: 167-184.

Wang X, Dong Z, Zhang J, Liu L. 2004a. Modern dust storms in China: an overview. Journal of Arid Environments 58: 559-574.

Wang X, Guo H, Chang Y, Zha L. 2004b. On paleo-drainage evolution in mid-late Epipleistocene based on radar remote sensing in north-eastern Ejin Banner, Inner Mongolia. Journal of Geographical Sciences 14: 235-241.

Wang Z, Uno I, Gong S, Zhang M, Akimoto H. 2007. Simulating soil-dust, sea-salt and sulphate aerosols in East Asia using Rams-online chemical transport model coupled with CAM (Canadian Aerosol Module). Air Pollution Modeling and Its Application 15: 243-251.

Washington R, Todd MC, Engelstaedter S, Mbainayel S, Mitchell F. 2006. Dust and the low-level circulation over the Bodélé Depression, Chad: observations from BoDEx 2005. Journal of Geophysical Research 111: D03201.

Weiss E, Marsh SE, Pfirman ES. 2001. Application of NOAA-AVHRR NDVI time-series data to assess changes in Saudi Arabia's rangelands. International Journal of Remote Sensing 22: 1005-1027. 
Wells KC, Witek M, Flatau P, Kreidenweis SM, Westphal DL. 2007. An analysis of seasonal surface dust aerosol concentrations in the western US (2001-2004): observations and model predictions. Atmospheric Environment 41: 6585-6597.

White K, Bullard JE. 2009. Abrasion control on dune colour: Muleshoe Dunes, SW USA. Geomorphology 105: 59-66.

William TH, Thomas G. 1996. Modelling NDVI from decadal rainfall data in the Northeast arid zone of Nigeria. Journal of Environmental Management 48: 249-261.

Wolfe SA, Nickling WG. 1993. The protective role of sparse vegetation in wind erosion. Progress in Physical Geography 17: 50-68.

Xu X, Levy JK, Zhaoui L, Hong C. 2006. An investigation of sand-dust storms events and land surface characteristic in China using NOAA NDVI data. Global and Planetary Change 52: 182-196.
Xu X, Xue L, Xue ZH, Xue F, Zeng OC. 2003. Correlation analysis between meteorological factors and the ratio of vegetation cover. Acta Ecologica Sinica 23: 221-230.

Yu F, Price K, Lee R, Ellis J. 1999. Monitoring the interannual variations of the grasslands bordering the eastern edge of the Gobi desert in central Asia with time-series NOAA/AVHRR data. In Proceedings of Pecora 14th and Landsatellite Information III, Denver, CO; 7-9.

Zender CS, Bian H, Newman D. 2003. Mineral Dust Entrainment And Deposition (DEAD) model: Description and 1990s dust climatology. Journal of Geophysical Research 108: 4416-4435.

Zeng H, Sui DZ, Ben Wu X. 2005. Human disturbances on landscape in protected areas: a case study of the Wolong Nature reserve. Ecological Research 20: 487-496. 